Analyzing Techniques for Increasing Power Transfer in the

\title{
Electric Grid
}

by

Kushal Dave

A Thesis Presented in Partial Fulfillment of the Requirements for the Degree Master of Science

Approved October 2012 by the Graduate Supervisory Committee:

Ravi Gorur, Chair

Gerald Heydt

Vijay Vittal

\section{ARIZONA STATE UNIVERSITY}

December 2012 


\begin{abstract}
The worldwide demand for electric energy is slated to increase by $80 \%$ between the years 1990 and 2040. In order to satisfy this increase in load, many new generators and transmission lines are planned. Implementations of various plans that can augment existing infrastructure have been hindered due to environmental constraints, public opposition and difficulties in obtaining right-of-way. As a result, stress on the present electrical infrastructure has increased, resulting in congestion within the system. The aim of this research is to analyze three techniques that could improve the power transfer capability of the present electric grid. These include line compaction, use of high temperature low sag conductors and high phase order systems. The above methods were selected as they could be readily employed without the need for additional right-of-way.

Results from the line compaction tests indicate that line compaction up to $30 \%$ is possible and this increases the power transfer capability up to 53\%. Additional advantages of employing line compaction are the reduction in electric and magnetic fields, increase in system stability and better voltage regulation.

High temperature low sag conductors that were applied on thermally limited lines were seen to increase the power transfer capability. However, a disadvantage of this technique was that the second most congested line, limits the power transfer capability of the system.
\end{abstract}


High phase (six phase) order system was noted to have several advantages over three phase system such as lower voltage requirement to transfer equal amount of power and lower electric and magnetic field across the right of way.

An IEEE 9 and 118 bus test system were used to evaluate the above mentioned techniques. 


\section{ACKNOWLEDGEMENTS}

I would like to first offer my sincerest gratitude to my advisor, Dr. Ravi Gorur, whose guidance and support has enabled me to develop an understanding of the subject. I also want to express my gratitude to Dr. Gerald Heydt and Dr. Vijay Vittal for their time and consideration in being a part of my graduate supervisory committee.

Financial assistance provided by the Western Electricity Coordinating Council (WECC) is greatly acknowledged.

I particularly want to thank my parents Mr. Kaushik Dave and Mrs. Mamta Dave for their constant inspiration and motivation to pursue my goals. I would also like to thank my project partners Nihal Mohan, Xianda Deng and all my friends for their constant encouragement and support. 
TABLE OF CONTENTS

Page

LIST OF TABLES ................................................................................. vii

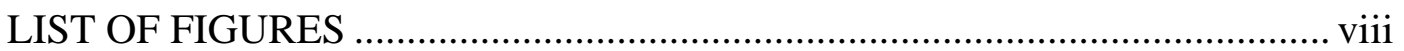

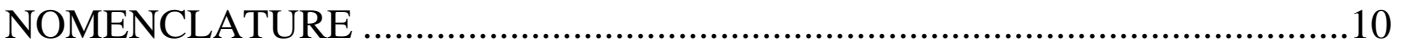

\section{CHAPTER}

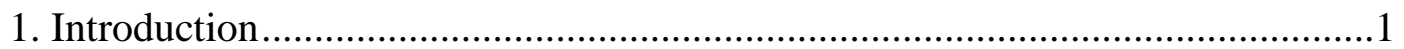

$1.1 \quad$ Overview of electric power system...............................................

1.2 Developments in power industry ................................................

$1.3 \quad$ Factors affecting transmission growth ...........................................

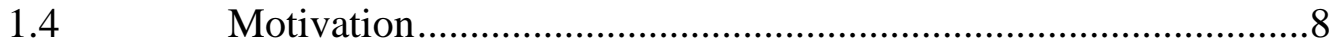

$1.5 \quad$ Techniques studied to increase power transfer ...............................

1.6 Organization of this thesis ..........................................................

2. Line parameters and power transfer limitations.............................................11

2.1. Introduction .........................................................................

2.2. Surge impedance loading .........................................................11

2.2.1 Line parameters calculation....................................12

2.3. Thermal and sag limits.............................................................17

2.4. Stability limits ......................................................................17

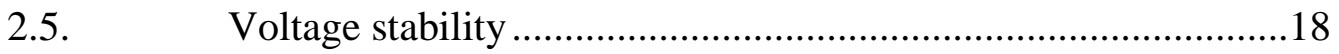

2.6. Limits on power transfer capability on line length .......................19 
3. Electric and magnetic fields.................................................................20

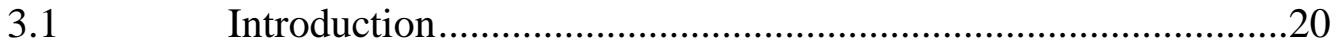

Electric field calculation ................................................21

Magnetic field calculation......................................................23

4. Techniques for increasing power transfer ...............................................26

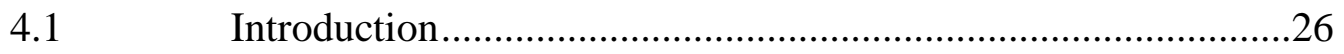

Line compaction...............................................................27

4.3 High temperature low sag conductors (HTLS) .........................36

High phase (six phase) order system .....................................37

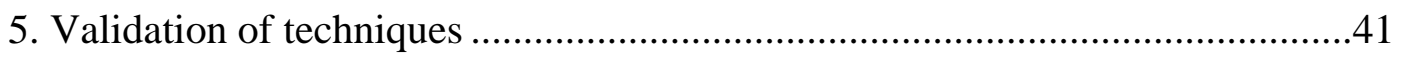

$5.1 \quad$ Objective and description ...............................................41

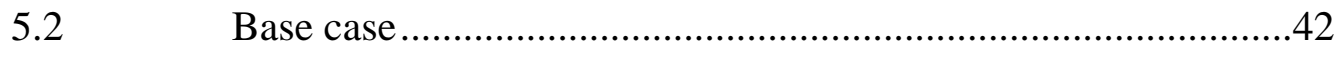

Case -1 : Line compaction................................................44

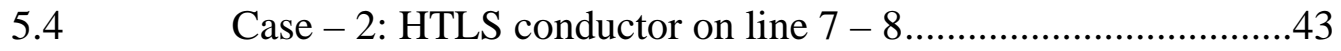

5.5 Case - 3: Converting line $7-8$ to high phase order system (six

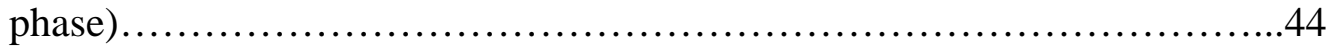

C.6 Case -4 : Transient stability analysis.................................45

5.7 Objective and description of the 118 bus test system ................47

C.8 $\quad$ Case -5 : Line compaction..............................................49

5.9 Case - 6: Application of HTLS conductors ...........................50 


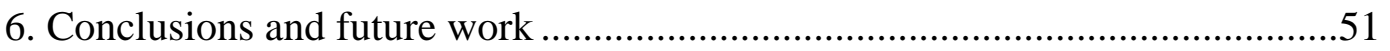

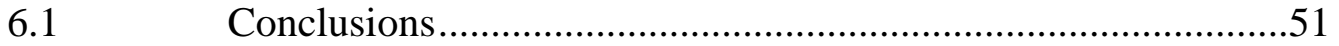

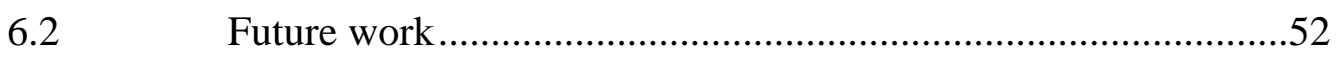

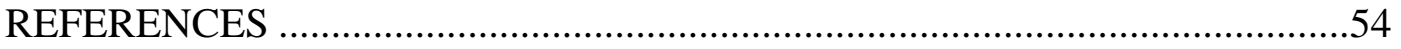

APPENDIX

A Standards for electric and magnetic field.................................................58

B Parameters for IEEE 9 bus system .........................................................60

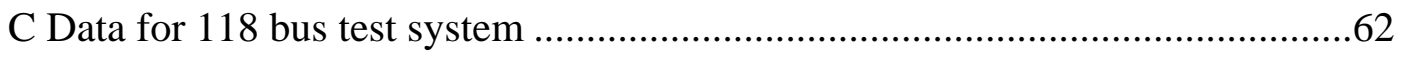




\section{LIST OF TABLES}

Table Page

2-1 Line parameters for the $230 \mathrm{kV}$ example .................................................. 17

4-1 Comparison of clearances with the minimum NESC requirement................ 29

4-2 Comparison of HTLS conductor with ACSR conductor (Drake) .................. 37

4-3 Relationship between line to line and line to ground voltage in high phase

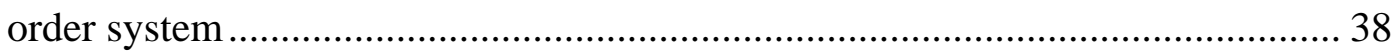

5-1 Line limits for nine bus test system .................................................. 42

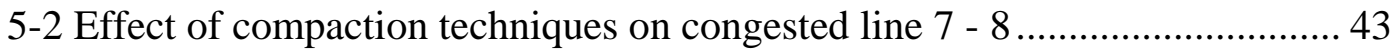

5-3 Impact of load increment on line congestion........................................... 44

5-4 Impact of load increment on line congestion.......................................... 45

5-5 Critical clearing time with and without line compaction ........................... 46

A-1Electric and magnetic field standards established by various states in the

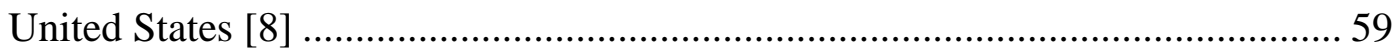

A-2 Occupational and public exposure by ICNIRP [36] ................................. 59

B-1Generator parameters for IEEE 9 bus test system ................................. 61

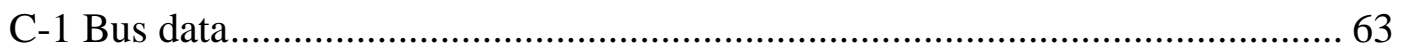

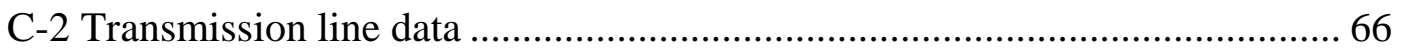

C-3 Violations in IEEE 118 bus test system .............................................. 72 


\section{LIST OF FIGURES}

Figure Page

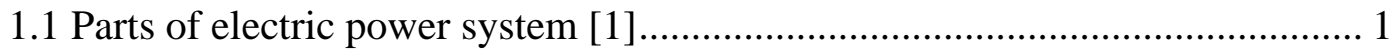

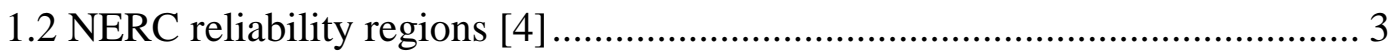

1.3 Capital invested as a percentage of electricity revenues [8] ......................... 7

1.4 United States investment in new electric power transmission [8] ................... 7

1.5 Transmission spending in United States in dollars adjusted to inflation [8] .... 8

2.1 Schematic of three phase horizontal configuration with earth return ............ 13

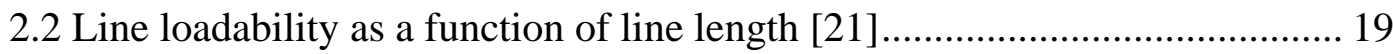

3.1 Electric field vectors due to phase $\mathrm{A}$ at any point in the space..................... 21

3.2 Electric field measured at $1 \mathrm{~m}$ above the ground level............................... 23

3.3 Magnetic field lines due to conductor A at any point in space ..................... 23

3.4 Magnetic field measured at $1 \mathrm{~m}$ above the ground level ............................ 25

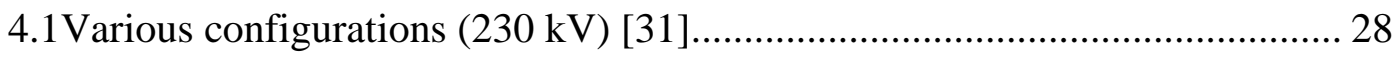

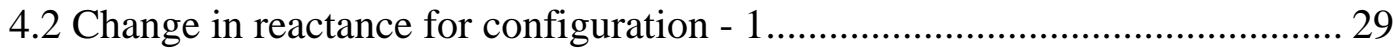

4.3 Change in reactance for configuration - 2................................................. 30

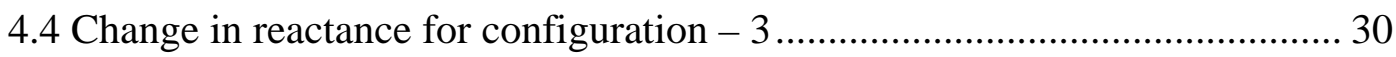

4.5 Electric and magnetic field plots for configuration -1 .............................. 31

4.6 Electric and magnetic field plots for configuration -2 ............................ 31

4.7 Electric and magnetic field plots for configuration -3 ............................. 32

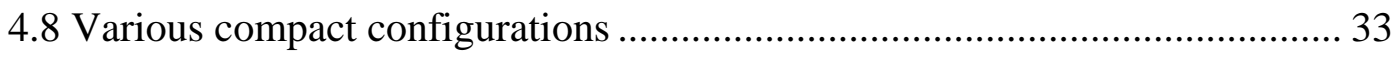

4.9 Change in reactance for various horizontal compact configurations.............. 33 
Figure

4.10 Change in reactance for various vertical compact configurations

4.11 Change in reactance for various double circuit vertical compact

configurations 34

4.12 Electric and magnetic field comparisons ............................................... 35

4.13 Voltage requirement for three phase double circuit and six phase single circuit for same amount of power transfer....................................................... 39

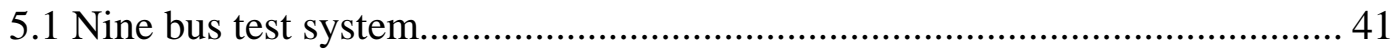

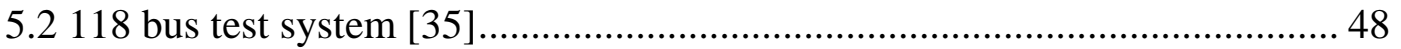

5.3 Line limit monitoring of IEEE 118 bus test system................................. 49 
NOMENCLATURE

\begin{tabular}{|c|c|}
\hline$A C A R$ & Aluminum Conductor Alloy Reinforced \\
\hline ACCC & Aluminum Conductor Composite Core \\
\hline ACCR & Aluminum Conductor Composite Reinforced \\
\hline ACGIH & American Conference of Governmental Industrial Hygienists \\
\hline ACSR & Aluminum Conductor Steel Reinforced \\
\hline ACSS & Aluminum Conductor Steel Supported \\
\hline$B$ & Magnetic field density \\
\hline$B I L$ & Basic insulation impulse level \\
\hline$B S L$ & Basic switching insulation level \\
\hline C & Capacitance matrix or capacitance \\
\hline CCT & Critical clearing time \\
\hline$D$ & Distance of the conductor \\
\hline$E$ & Electric field vector \\
\hline ERCOT & Electric Reliability Council of Texas \\
\hline$f$ & Frequency \\
\hline GMR & Geometric Mean Radius \\
\hline$h$ & Depth of conductor \\
\hline$H$ & Magnetic field intensity \\
\hline HTLS & High Temperature Low Sag \\
\hline ICNIRP & $\begin{array}{l}\text { International Commission on Non-ionizing Radiation Protec- } \\
\text { tion }\end{array}$ \\
\hline
\end{tabular}




\begin{tabular}{|c|c|}
\hline$I_{\text {con }}$ & Current through the conductor \\
\hline$L$ & Inductance matrix or inductance \\
\hline NERC & North American Electric Reliability Corporation \\
\hline NESC & National Electrical Safety Code \\
\hline$p$ & Potential coefficient matrix \\
\hline$P_{\text {sil }}$ & Surge impedance loading \\
\hline$Q$ & Charge on conductor or charge matrix \\
\hline$\overline{Q_{c}}$ & Charge matrix \\
\hline$r$ & Resistance matrix \\
\hline$R P S$ & Renewable Portfolio Standards \\
\hline$V_{l l}$ & Line-to-line voltage \\
\hline$V_{l n}$ & Voltage matrix \\
\hline WECC & Western Electricity Coordinating Council \\
\hline$X$ & Reactance matrix \\
\hline$X_{m}$ & Mutual reactance \\
\hline$X_{s}$ & Self reactance \\
\hline$Z$ & Impedance matrix \\
\hline$Z_{s}$ & Surge impedance \\
\hline$\delta$ & Power angle \\
\hline$\mu_{o}$ & Permeability of free space \\
\hline$\rho$ & Soil resistivity \\
\hline$\omega$ & Angular frequency \\
\hline
\end{tabular}


\begin{tabular}{l|l}
$\Phi$ & Flux linkage
\end{tabular} 


\section{Chapter 1. Introduction}

\subsection{Overview of electric power system}

The electric power grid is divided into three major sections namely, generation, transmission and distribution as shown in Figure 1.1 [1]. Generating stations generate electric energy using conventional fuels like coal, nuclear, oil and natural gas or non-conventional fuels like wind, solar and biogas. The generated voltage is in the range of $11 \mathrm{kV}-28 \mathrm{kV}$.

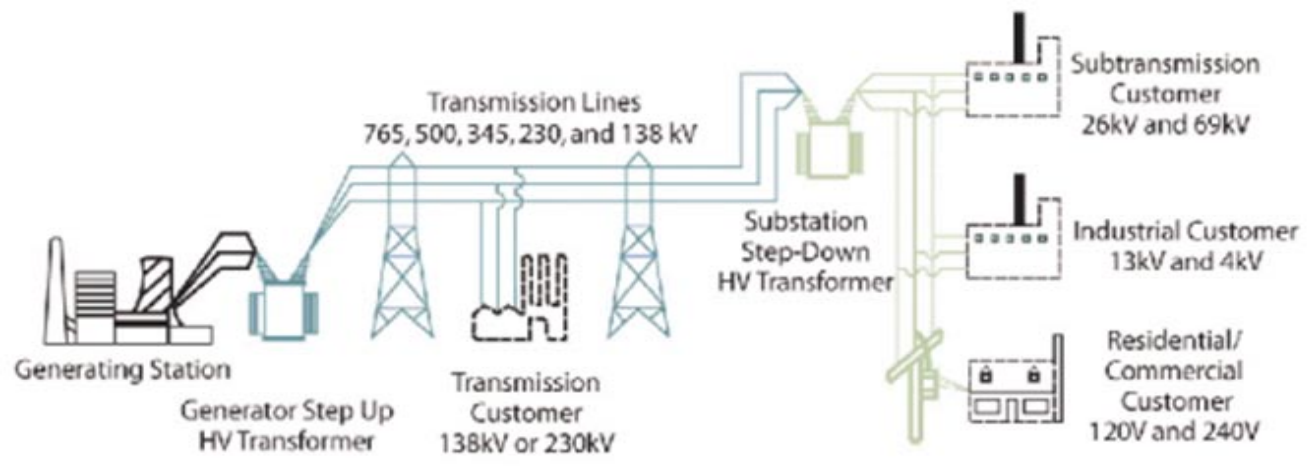

Figure 1.1 Parts of electric power system [1]

Transmission systems transfer electric energy in bulk from generating stations to the load centers. Higher transmission voltage levels enable more power transfer over long distances. Presently, $765 \mathrm{kV}$ is the highest transmission system voltage in the United States, while countries like China and India are using $1000 \mathrm{kV}$ and $1200 \mathrm{kV}$ systems [2][3]. A major portion of transmission system in the United States is operated on alternating current (A.C) while the rest is on direct current (D.C). The distribution systems are the load centers where higher voltages are stepped down to the required lower voltages $(480 \mathrm{~V}, 11 \mathrm{kV}, 33 \mathrm{kV}$ and $69 \mathrm{kV})$ for 
utilization. The load centers primarily consist of residential, commercial and industrial customers.

\subsection{Developments in power industry}

The electric grid was initially operated as a vertically integrated system, where in generation, transmission and distribution systems were owned by the same utility. Later, the utilities decided to jointly own power plants and interconnect neighboring grids to facilitate the power sales and increase reliability of the system. These developments led to the formation of an electric grid with three major interconnections in the United States [1][4]. The three interconnections are Western, Eastern and Electric Reliability Council of Texas (ERCOT) interconnection as shown in Figure 1.2. Since 1980s, the industry has been going through a process of deregulation and Independent System Operators were established at few regions. In order to maintain safe and reliable operation of the electric grid, the North American Electric Reliability Corporation (NERC) has established eight regions as shown in Figure 1.2 [4]. The Western interconnection region is operated by Western Electricity Coordinating Council (WECC); the Eastern interconnection regions are operated by six regions namely Midwest Reliability Organization (MRO), Northeast Power Coordinating Council (NPCC), Reliability First Corporation (RFC), Southwest Power Pool (SPP), SERC Reliability Corporation (SERC) and Florida Reliability Coordinating Council (FRCC) while the ERCOT interconnection region is operated by Texas Regional Entity [4]. 


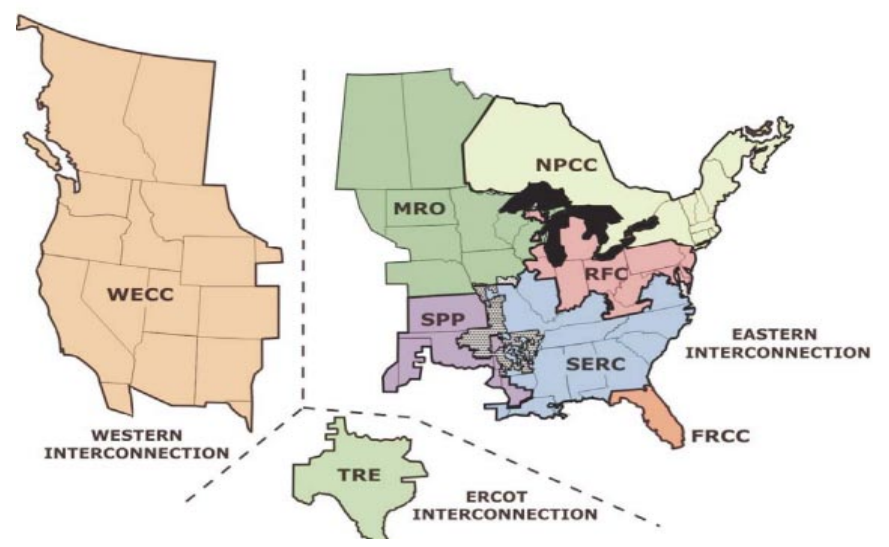

Figure 1.2 NERC reliability regions [4]

In recent years, the industry has faced many problems such as aging infrastructure, lack of investment in maintenance, higher legal and environmental requirements, increased cost of right-of-way and need for better grid security. Moreover, the governmental agencies have established renewable portfolio standards (RPS) under which the utilities are required to generate a fixed portion of electricity using renewable resources [5][6]. It is therefore paramount to have an adequate transmission system. The effects of present trends on each division of power industry are detailed as follows.

\section{Generation}

In a vertically integrated system, long term planning was coordinated by a single utility to maintain generation and transmission adequacy with increase in load. Due to deregulation, new generation was permitted to enter the market with free access to transmission system to provide energy at any part of the grid. As a result, new market participants have established generating stations based on load 
growth, return on investment and available resources rather than grid requirements and security. Therefore, transmission company planners spend most of their time in altering and accommodating the new generating stations in the electric grid, resulting in lack of coordinated long term planning required to secure future energy requirements [7][8].

\section{Transmission}

A transmission system is operated in accordance with the established regulation and maintaining stable network conditions. Since, all generating stations have free access to the transmission grid, maintaining transmission adequacy is one of the many challenges faced by the power industry. With the continuously increasing demand for electric energy, the growth of the transmission system is imperative. Many factors have affected the transmission system growth. All these factors were discussed in detail in Section 1.3.

\section{Distribution}

Initially, the distribution system had an effect similar to the transmission system. This trend was alleviated by companies offering quality and reliable energy supply. Other significant changes were the new type of meters for flexible tariff and establishment of distributed generation to satisfy the RPS standards [8].

\subsection{Factors affecting transmission growth}

Various factors that boost or restrict the transmission growth are listed below: 
- Load growth: The most important reason for transmission growth is increase in electrical load. The load growth is due to increase in population, urbanization and industrialization. A report by Exxon Mobil has projected the demand for electricity to grow by $80 \%$ between the years 1990 - 2040[9]. The demand in the United States has increased by 25\% since 1990; and developing countries such as Brazil, China, India and South Africa have increased rapidly in recent years [10]. This increase in demand has been satisfied by increasing the number of generating stations, modifying existing transmission lines and by building new transmission lines [7][9][10].

- Generator location: Due to environmental constraints, availability of land, resources and public resistance, generating stations were established at a location distant from the load centers. Moreover, the renewable generation required to satisfy RPS has boosted the requirement for transmission growth.

- Reliability: Due to the interconnected nature of power systems, an increase in load is achieved by raising the power flow on inter-tie lines instead of adding local generation and transmission system. This requires higher reliability margin and transmission line capability as the difference between peak load and generating capability decreases. Moreover, the NERC standards require that the electric grid operate reliably despite loss of any one element (i.e. largest generator, transmission line and transformer). This has necessitated additional lines to be connected in the grid. 
- RPS requirement: Many governmental agencies across the United States and world have established a standard that requires some portion of the electric energy be generated using renewable resources [5][6]. These resources are intermittent in nature and are usually at distant location from the load centers. Hence, in order to incorporate renewable energy and maintain reliable supply, the transmission system needs to be upgraded.

- Environmental and legal issues: Environmental effects like land usage, ecological effects, electric and magnetic field effects have to be considered while designing a transmission line. Standards or guidelines were set by various governmental agencies to minimize the effects of electric and magnetic fields arising from transmission lines [11]. Even though all these factors are accounted for during line design and routing, a significant number of planned lines have been delayed, re-routed or cancelled due to legal intervention. These have increased the overall cost of building new lines [4].

- Investment in infrastructure: In a vertically integrated system, utilities build the required lines to ensure there is adequate transmission system. After deregulation, many companies jointly own the transmission grid. Since most companies focus mainly on profits and return to shareholders, they prefer an increase in the utilization of current assets rather than investing in newer ones requiring higher investments. Figure 1.3 indicates the capital invested in transmission network as a percentage of the United States electricity revenues [12]. Figure 1.4 indicates that even though the peak demand has increased, the 
investment in transmission infrastructure has reduced [12]. This disparity is expected to widen with increase in load.

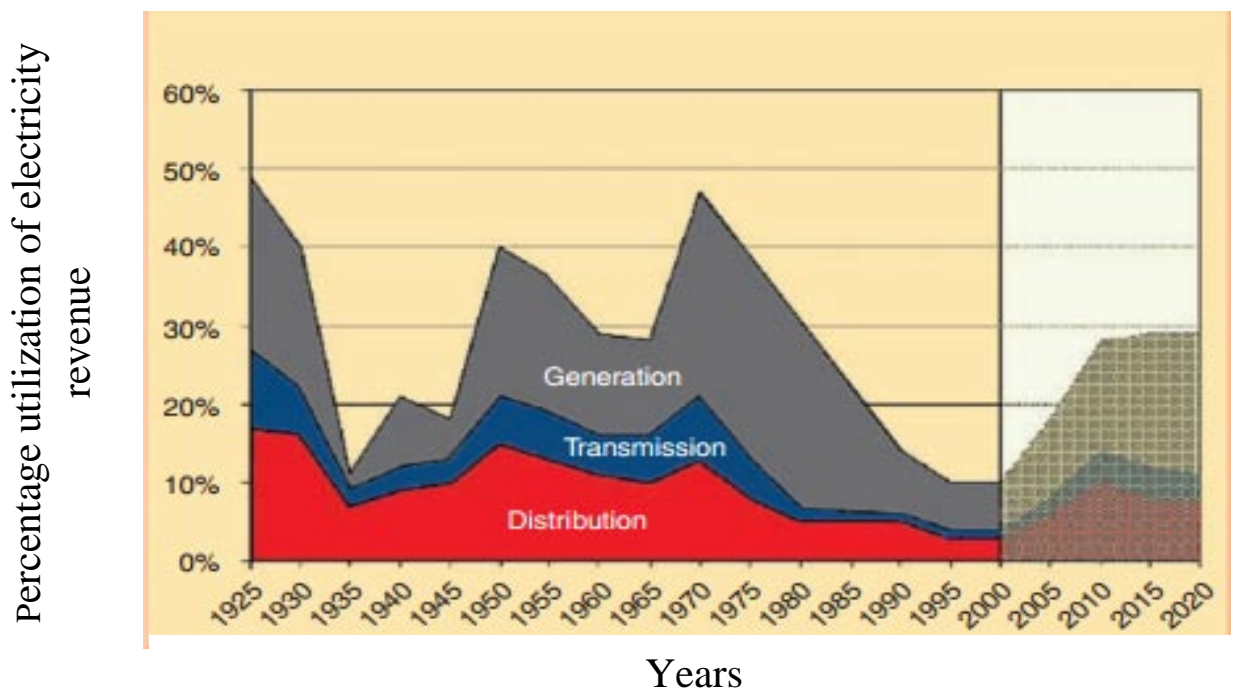

Figure 1.3 Capital invested as a percentage of electricity revenues [8]

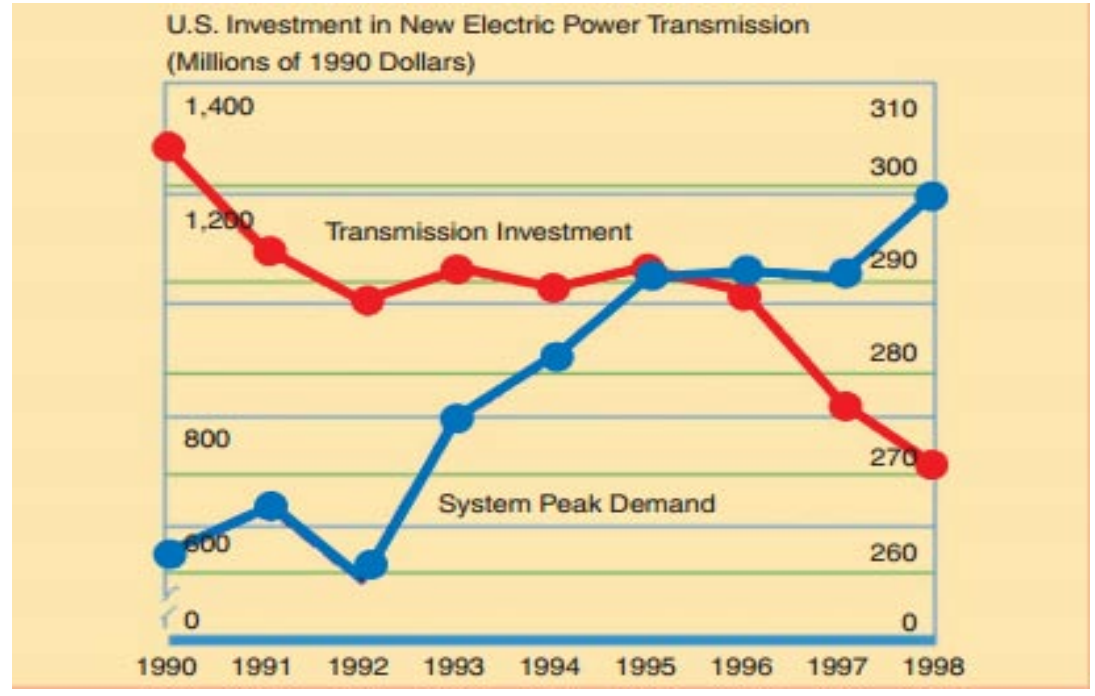

Figure 1.4 United States investment in new electric power transmission [8]

- Maintenance: The majority of the expansion of the electric grid occurred between the 1950s and 1970s. With aging infrastructure, the industry was expected to focus on increasing the life span of the grid. However, total trans- 
mission maintenance dollars spent in the United States between 1990s and 2002 has reduced by 20\% as shown in Figure 1.5 [8].

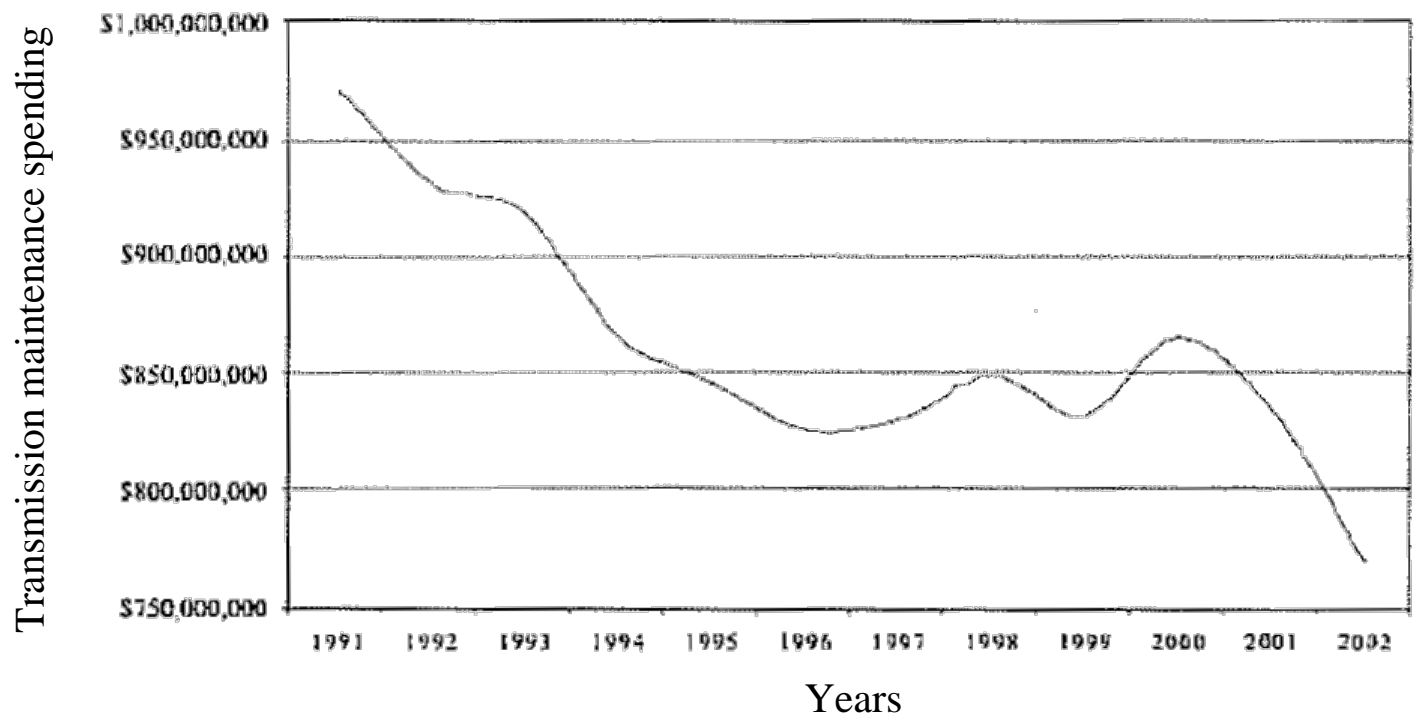

Figure 1.5 Transmission spending in United States in dollars adjusted to inflation [8]

\subsection{Motivation}

Low investment in building new transmission lines has gradually congested the existing infrastructure. Studies carried out by WECC, United States Department of Energy (DOE) and ERCOT indicate various congested lines in the system [13][14]. Congestion limits the power transfer capability of the transmission system and in order to alleviate the congestion and secure the future load demand, several transmission plans have been proposed by various organizations [15][16]. The above fact is supported by a study carried out by the Edison Electric Institute that stated that a high investment is required to mitigate the ongoing problems [17]. Adding new infrastructure is a long-term process with various constraints as discussed in Section 1.3. This research focuses on an alternate 
short-term process for improving power transfer capability by analyzing known and recently developed technologies for providing a solution to the problem.

\subsection{Techniques studied to increase power transfer}

Three techniques were studied that help to increase the power transfer capability of the system. 1) Line compaction 2) High phase (six-phase) order systems and 3) High temperature low sag (HTLS) conductors. These techniques were selected because they use the existing or reduced right of way. A detailed discussion of these techniques is carried out in chapter 4.

\subsection{Organization of this thesis}

This work is organized into six chapters. Chapters 2 and 3 present basic concepts of line parameters, electric and magnetic field calculation, power transfer capability and limitations of the line.

Chapter 4 describes in detail, the three techniques discussed for increasing power transfer capability of the system. Chapters 5 show the application of various techniques in the IEEE 9 and 118 bus test case systems and benefits achieved.

Chapter 6 presents contributions, conclusions drawn from the test systems and future studies required for the implementation of these techniques.

There are three appendix sections at the end of this thesis. Appendix - A provides different electric and magnetic field standard established by various organizations. Appendix - B provides the dynamic parameters for the generators in 
IEEE 9-bus test system. Appendix - C provides the system parameters for IEEE 118 bus test system. 
Chapter 2. Line parameters and power transfer limitations

\subsection{Introduction}

Power transfer capability of a high voltage transmission line depends on various factors like surge impedance loading, thermal and sag limits, stability limits and voltage stability [7]. Surge impedance loading depends on the transmission line parameters i.e. inductance and capacitance. While thermal and sag limits determine the maximum current rating of the conductor and the minimum clearances required from conductor to ground. The rotor angle stability is the ability of an interconnected system to remain in synchronism when subjected to a disturbance. Voltage stability indicates voltage variations at the buses across the system in case of any event. This chapter explains in detail the limitations on the power transfer capability of a transmission lines.

\subsection{Surge impedance loading}

The power transfer capability of a transmission line could be approximated by knowing the surge impedance. This characteristic of the line is called surge impedance loading $\left(P_{\text {sil }}\right)$. Equation 2.1 shows the power transfer capability of a three-phase transmission line with a surge impedance of $\left(Z_{s}\right)$ and rated lineto-line voltage $\left(V_{l l}\right)$. The surge impedance of a line depends on the inductance and capacitance of the line as shown in Equation 2.2,

$$
P_{s i l}=\frac{\left|V_{l l}\right|^{2}}{Z_{s}}
$$




$$
Z_{s}=\sqrt{\frac{L}{C}}
$$

This shows that the line parameters are important factor in determining the power transfer capability of a transmission line.

\subsubsection{Line parameters calculation}

Transmission line parameters depend on various factors such as, conductor selection, soil resistivity, temperature and frequency. The factors like soil resistivity, temperature and frequency could be considered as constant. A program developed in MATLAB using the equations given in this section to obtain the line parameters for three phase single circuit, three phase double circuit and six phase single circuit lines.

Impedance calculation: The impedance calculation for the circuit depends on the conductor location and selection. Figure 2.1 indicates the schematic three phase horizontal configuration with shield wire. In order to replicate the effect of return current caused by earth, the earth return effects are replaced by placing imaginary return conductors below ground level as shown in Figure 2.1. 


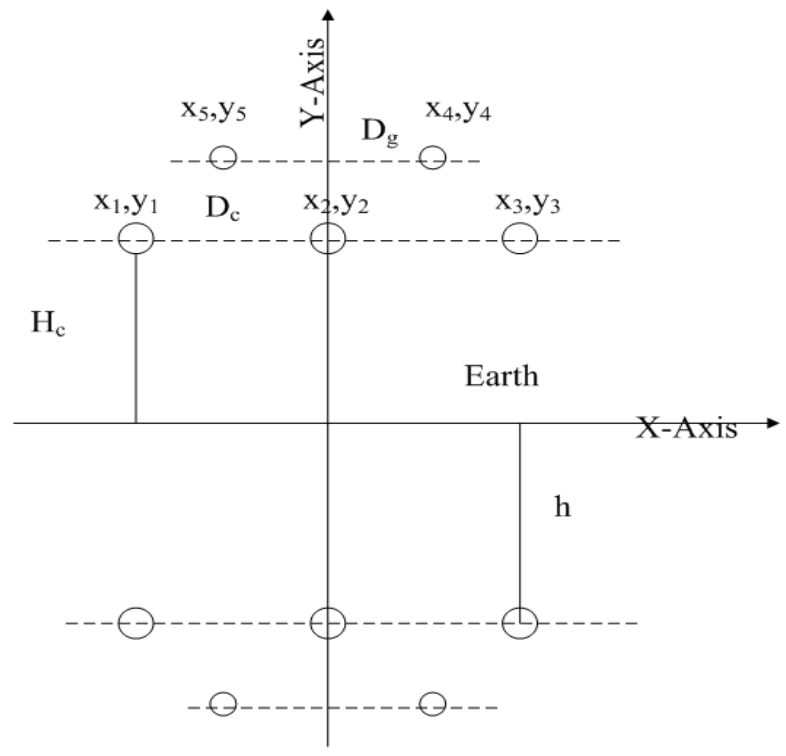

Figure 2.1 Schematic of three phase horizontal configuration with earth return The depth of the return conductor is a function of soil resistivity and system frequency is,

$$
h=658.5 \sqrt{\rho / f}
$$

where,

$$
\begin{aligned}
& \rho=\text { soil resistivity }(\Omega / \mathrm{m}) \\
& f=\text { frequency }(\mathrm{Hz}) \\
& h=\operatorname{depth} \text { of conductor }(\mathrm{m})
\end{aligned}
$$

Hence, the flux linkage ( $\phi$ ) of conductors could be represented by,

$$
\phi_{(x, y)}=I_{\operatorname{con}(x)} \frac{\mu_{0}}{2 \pi} \ln \left(\frac{h}{G M R}\right)+I_{\text {con }(y)} \frac{\mu_{0}}{2 \pi} \ln \left(\frac{h}{D_{(x, y)}}\right)
$$

where,

$$
\begin{aligned}
& \Phi=\text { a matrix of flux linkage between conductors. (Wb) } \\
& I_{\text {con }}=\text { current through conductor (A) }
\end{aligned}
$$




$$
\begin{aligned}
& G M R=\text { Geometrical Mean Radius of conductor in meters. } \\
& D=\text { distance of conductors in meters if } x \neq y \text {; GMR of conductor if } \\
& x=y
\end{aligned}
$$

The reactance of a three-phase single circuit line is calculated using

$$
X_{(x, y)}=\omega \frac{\phi_{(x, y)}}{I_{c o n}}
$$

Where,

$$
\begin{aligned}
& X=\text { reactance matrix in }(\Omega / \text { mile }) \\
& \omega=\text { angular frequency }(\mathrm{rad} / \mathrm{sec})
\end{aligned}
$$

Equation 2.6 and 2.7 give the resistance matrix for the line

$$
\begin{gathered}
r_{(x, y)}=r_{\text {ground }} ; \text { where } x \neq y \\
r_{(x, y)}=r_{\text {ground }}+r_{\text {cond }} ; \text { where } x=y \\
r=\text { resistance matrix }(\Omega / \text { mile })
\end{gathered}
$$

Combining the Equation 2.5, 2.6 and 2.7 gives the impedance matrix as shown by,

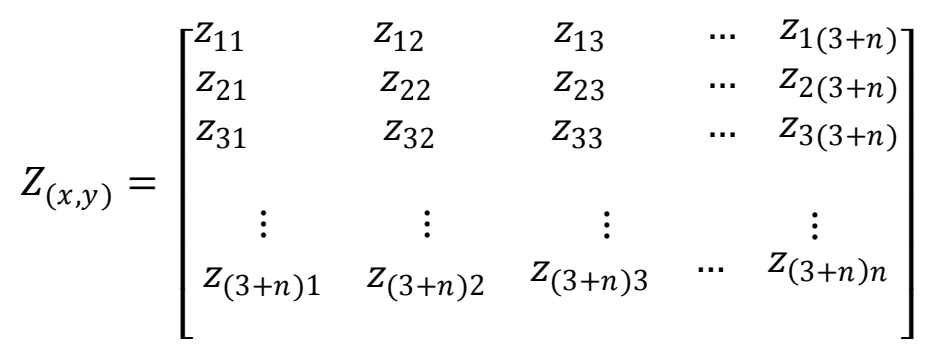

A Gauss elimination technique was applied to Equation 2.8 to obtain the reactance matrix,

$$
Z=\left[\begin{array}{lll}
Z_{11} & Z_{12} & Z_{13} \\
Z_{21} & Z_{22} & Z_{23} \\
Z_{31} & Z_{32} & Z_{33}
\end{array}\right] \Omega / \text { mile }
$$


As the transmission line was considered completely transposed, from Equation 2.9

$$
\begin{gathered}
Z_{11}=Z_{22}=Z_{33}=Z_{s} \text { (Self impedance) } \\
Z_{12}=Z_{13}=Z_{21}=Z_{23}=Z_{31}=Z_{32}=Z_{m} \text { (Mutual impedance). }
\end{gathered}
$$

A simplistic formula for the positive sequence reactance is given as shown in Equation 2.10.

$$
X_{1}=X_{s}-X_{m}
$$

Similarly, an impedance calculation could also be repeated for a three phase double circuit as well as six-phase single circuit.

Capacitance calculation: The capacitance of the line depends on the height and distance between the conductors. Capacitance effect is observed between conductors as well as between the conductor and ground. Energization of the line causes charges on the conductor and ground. The effect of ground charges was simulated by placing imaginary conductors as shown in Figure 2.1. This image conductor carries negative charge. The voltage difference generated by the charges between any two conductors is given by,

$$
\begin{gathered}
{\left[V_{l n}\right]=[p] \times\left[Q_{c}\right]} \\
{\left[p_{(x, y)}\right]=\frac{1}{2 \pi \varepsilon_{0}} \times \ln \left(\frac{D_{(x, y)}}{d_{(x, y)}}\right)}
\end{gathered}
$$

where,

$$
\begin{aligned}
& V_{l n}=\text { Voltage vector of size } n \times 1 \text {, where } \mathrm{n} \text { is the number of conductors. } \\
& p=\text { Potential coefficient matrix of size } n \times n \text {. }
\end{aligned}
$$




$$
\begin{aligned}
& d=\text { Distance matrix of charge conductors }(n \times n) \\
& D=\text { Distance matrix of charge conductors and return conductors }(n \times n) \\
& Q_{c}=\text { Charge matrix on conductors of size } n \times 1
\end{aligned}
$$

In Equation 2.11 voltages on the conductors and the potential coefficient matrix are known and hence charges on conductor are obtained as

$$
\begin{gathered}
{\left[Q_{c}\right]=[C] \times[V]} \\
{[C]=[p]^{-1}}
\end{gathered}
$$

Where,

$$
C=\text { Capacitance matrix of size } n \times n \text {. }
$$

A Gauss elimination method was applied to the capacitance matrix to obtain the capacitance for a three-phase single circuit line resulting in a 3 x 3 matrix,

$$
C=\left[\begin{array}{lll}
C_{11} & C_{12} & C_{13} \\
C_{21} & C_{22} & C_{23} \\
C_{31} & C_{32} & C_{33}
\end{array}\right] \mathrm{nF} / \text { mile }
$$

Similarly, the capacitance for a three phase double circuit and six-phase single circuit line could be calculated.

Consider an example of a $230 \mathrm{kV}$ horizontal configuration having a phase-tophase distance of $4.8 \mathrm{~m}$, phase to tower distance of $2.4 \mathrm{~m}$ and height of the conductor being $10 \mathrm{~m}$ using a Bluebird conductor. The impedance, capacitance and the surge impedance loading for that line were obtained using Equations 2.9, 2.15 and 2.2 respectively is shown in Table $2-1$ 
Table 2-1 Line parameters for the $230 \mathrm{kV}$ example

\begin{tabular}{|c|c|}
\hline Resistance & $0.0505(\Omega /$ mile $)$ \\
\hline Reactance & $0.7064(\Omega /$ mile $)$ \\
\hline Capacitance & $16.23(\mathrm{nF} / \mathrm{mile})$ \\
\hline Surge impedance & $339.73 \Omega$ \\
\hline Surge impedance loading & $269.7 \mathrm{MW}$ \\
\hline
\end{tabular}

\subsection{Thermal and sag limits}

The bare self-supporting overhead conductors of a high voltage transmission line carry high current. As the current carried by the conductor increases, the temperature of the conductor increases resulting in its elongation. This elongation reduces the conductor height from the ground level. A minimum distance between conductor height and ground has to be maintained. National Electrical Safety Code (NESC) standardizes the minimum clearance for safe live line operation and maintenance [18]. The other limitations are the temperature and current carrying capacity of the conductors. The maximum allowable temperature for an ACSR conductor is $75^{\circ} \mathrm{C}\left(167^{\circ} \mathrm{F}\right)$. However, due to thermal heating the actual temperature might go higher than that desired due to extreme weather conditions limiting the current carrying capacity on the line. For example, the current carrying capacity of drake conductor is $900 \mathrm{~A}$ at $75^{\circ} \mathrm{C}$ [19].

\subsection{Stability limits}

The rotor angle stability is ability of an interconnected power system to get back in synchronism after occurrence of an event. Transmission system is de- 
signed such that all generators operate in synchronism in steady as well as in transient state condition. Hence, it is important to consider the stability criteria for obtaining the maximum power transfer capability of a transmission line. It is known that power transfer over a transmission line, connected to a larger system on both ends, is inversely proportional to the reactance and directly proportional to the power angle $\delta$ as given by Equation 2.16. Thus, reactance sets a limit on the maximum power transmitted over a high voltage transmission line [7][20],

$$
P=\frac{V_{1} V_{2}}{X} \sin \delta
$$

Under steady state condition, the maximum power transfer occurs with $\delta=90^{\circ}$. However, a transmission system operating with many synchronous machines must withstand abrupt changes in generation or load, faults on the system resulting in loss of generation, transmission line or load. These variations cause transient effect on system voltages and angles. Therefore, the observed power angle is much lesser than $90^{\circ}$. Equal area criteria determines the maximum operating condition which reduces the power angle operating in the range of $30^{\circ}$ to $45^{\circ}[7][8][20][21]$.

\subsection{Voltage stability}

Voltage stability indicates the ability of power system to attain a stable voltage level after any change in load or loss of an element in the system [22]. The accepted voltage variation at the bus level is $\pm 5 \%$ of the rated voltage [7][8]. A transmission line carrying current has a voltage drop due to resistance and reactance of the line. This results in a lower receiving end voltage $\left(V_{2}\right)$ as compared to 
sending end voltage $\left(V_{1}\right)$. The percentage difference between the sending end voltage and receiving end voltage is called voltage regulation. This difference is kept low, as power transfer is directly proportional to the product of sending and receiving end voltages as shown in Equation 2.16

2.6. Limits on power transfer capability on line length

Various power transfer capability limitations were discussed in the previous sections. The role of each factor on the power transfer capability is a function of line length. As shown in Figure 2.2 the primary limiting factor for power transfer on a short transmission line is thermal and sag limits while for medium and long transmission lines voltage regulation and stability limit are considered respectively [21].

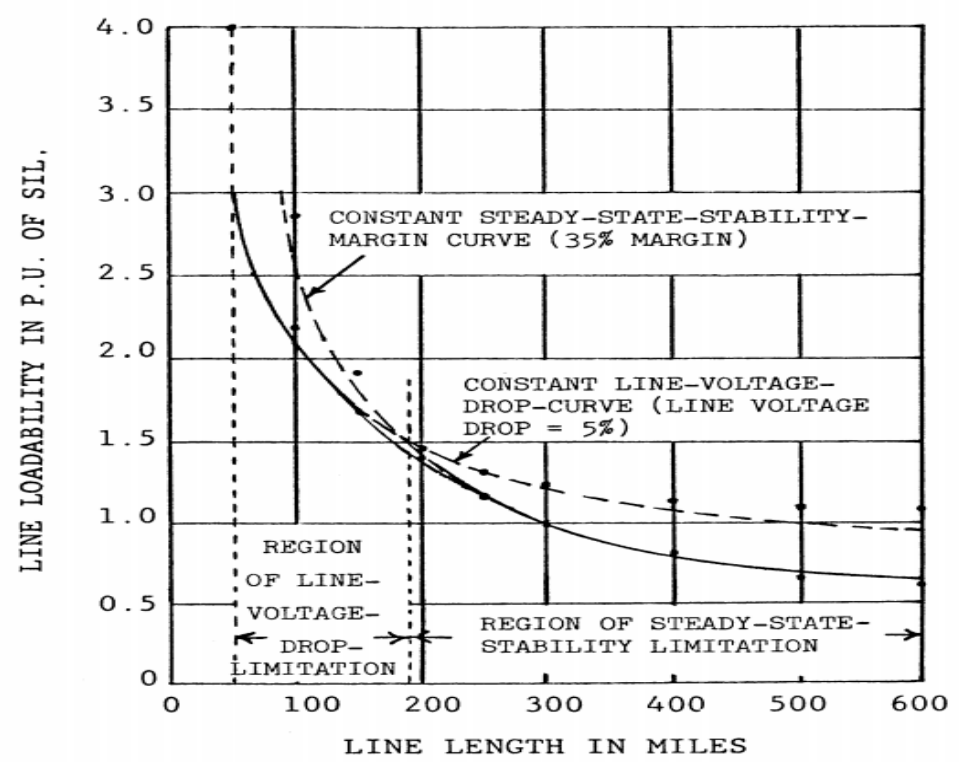

Figure 2.2 Line loadability as a function of line length [21] 


\section{Chapter 3. Electric and magnetic fields}

\subsection{Introduction}

Electric and magnetic field are the factors considered while designing transmission lines. The electric and magnetic field strength determines the corona, radio and audible noise interferences [7][8]. In recent years, a lot of research has been conducted on electric and magnetic field effects on human body [23][24]. As a result many states across the United States and countries across the globe have imposed limitations on electric and magnetic strength at the edge of the right of way [25][26]. For example, the State of New York has a standard established for electric and magnetic field strength of $1.6 \mathrm{kV} / \mathrm{m}$ and $200 \mathrm{mG} / \mathrm{m}$ respectively at the edge of the right of way [8]. Two organizations (International Commission on Non-Ionizing Radiation Protection (ICNIRP) 1998 and the American Conference of Governmental Industrial Hygienists (ACGIH)) were established to standardize operational and public exposure of electric and magnetic field. The standards for maximum public and occupational exposure to electric and magnetic field are shown in Appendix A. Therefore, there is a need to study the effect of electric and magnetic field in the present scenario. A MATLAB program is developed using the equations given in this chapter to calculate electric and magnetic field at any point in space [7][8]. 


\subsection{Electric field calculation}

Electric fields in nearby area of AC transmission line are calculated assuming no free charge in space. The charges on the conductors $(Q)$ are determined through the voltage $(V)$ matrix and Maxwell potential coefficient $(P)$ matrix as shown in Equation 3.1

$$
[Q]=[P]^{-1}[V] \text {. }
$$

The charge matrix can be written in terms of its real and imaginary components as shown in equation 3.2.

$$
[Q]=\left[Q_{r}\right]+j\left[Q_{i}\right] .
$$

Once the charges on the conductors are known, for any point $P(x, y)$ in space, the electric field can be calculated. The electric field due to conductor A and its image conductor as shown in Figure 3.1 is given by,

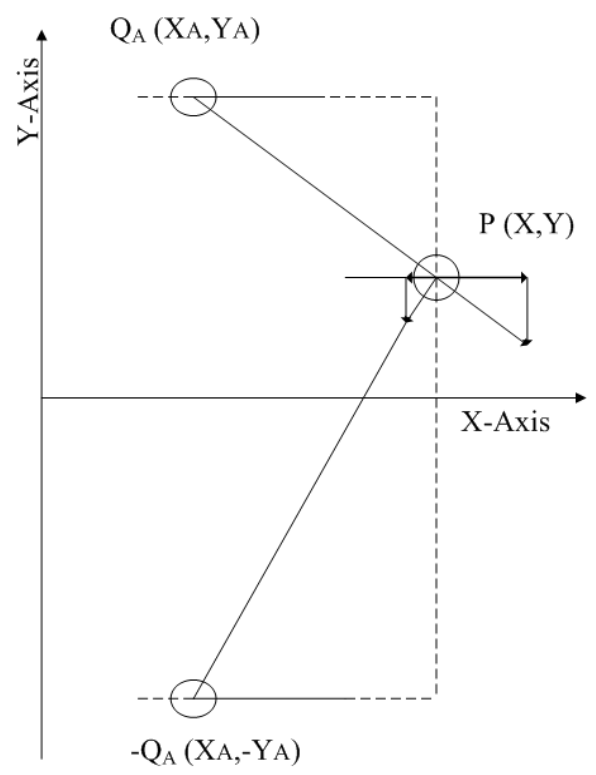

Figure 3.1 Electric field vectors due to phase A at any point in the space 


$$
\overrightarrow{E_{A}}=E_{x, A} \overrightarrow{u_{x}}+E_{y, A} \overrightarrow{u_{y}}
$$

Where,

$E_{x, A}$ and $E_{y, A}$ are the electric field magnitudes given by Equation 3.4 and 3.5 respectively, while $\overrightarrow{u_{x}}$ and $\overrightarrow{u_{y}}$ are the unit vectors along the horizontal and vertical axis respectively.

$$
\begin{aligned}
& E_{x, A}=\frac{\left(q_{r a}+j q_{i a}\right)\left(x-x_{a}\right)}{2 \pi \epsilon\left[\left(x-x_{a}\right)^{2}+\left(y-y_{a}\right)^{2}\right]}-\frac{\left(q_{r a}+j q_{i a}\right)\left(x-x_{a}\right)}{2 \pi \epsilon\left[\left(x-x_{a}\right)^{2}+\left(y+y_{a}\right)^{2}\right]} \\
& E_{y, A}=\frac{\left(q_{r a}+j q_{i a}\right)\left(y-y_{a}\right)}{2 \pi \epsilon\left[\left(x-x_{a}\right)^{2}+\left(y-y_{a}\right)^{2}\right]}-\frac{\left(q_{r a}+j q_{i a}\right)\left(y+y_{a}\right)}{2 \pi \epsilon\left[\left(x-x_{a}\right)^{2}+\left(y+y_{a}\right)^{2}\right]}
\end{aligned}
$$

Similarly, horizontal and vertical components of electric field are calculated for conductors B and C respectively. The total horizontal and vertical components $\vec{E}_{x}$ and $\vec{E}_{y}$ due to three conductors are calculated as per Equations 3.6 and 3.7 respectively. Equation 3.8 gives the magnitude of the total electric field caused due to three conductors at a point $P$ in space,

$$
\begin{aligned}
& \overrightarrow{E_{x}}=\overrightarrow{E_{x, A}}+\overrightarrow{E_{x, B}}+\cdots \\
& \overrightarrow{E_{y}}=\overrightarrow{E_{y, A}}+\overrightarrow{E_{y, B}}+\cdots \\
& |E|=\sqrt{\left(E_{x}\right)^{2}+\left(E_{y}\right)^{2}}
\end{aligned}
$$

Using the above equations the electric field was calculated for the example configuration discussed in Chapter 2. The electric field was calculated at $1 \mathrm{~m}$ above the ground level at mid - span with maximum sag of $1.1 \mathrm{~m}$. Figure 3.2 indicates the electric field plot across the right of way for the example configuration. 


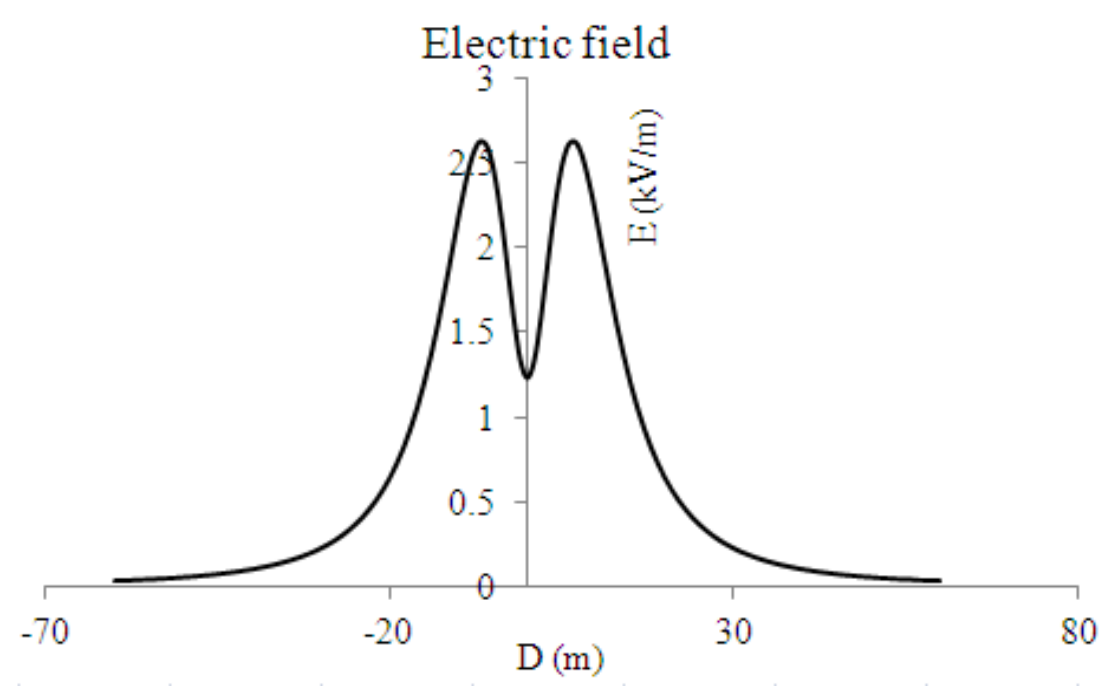

Figure 3.2 Electric field measured at $1 \mathrm{~m}$ above the ground level

\subsection{Magnetic field calculation}

The magnetic field of a transmission line was calculated using a two dimensional analysis of parallel lines over a flat earth. Figure 3.3 shows a conductor $A\left(x_{A}, y_{A}\right)$ carrying a current $I_{A}$. Equation 3.9 gives the magnetic field strength at any arbitrary point $P(\mathrm{x}, \mathrm{y})$ in the plane due to the current carrying conductor.

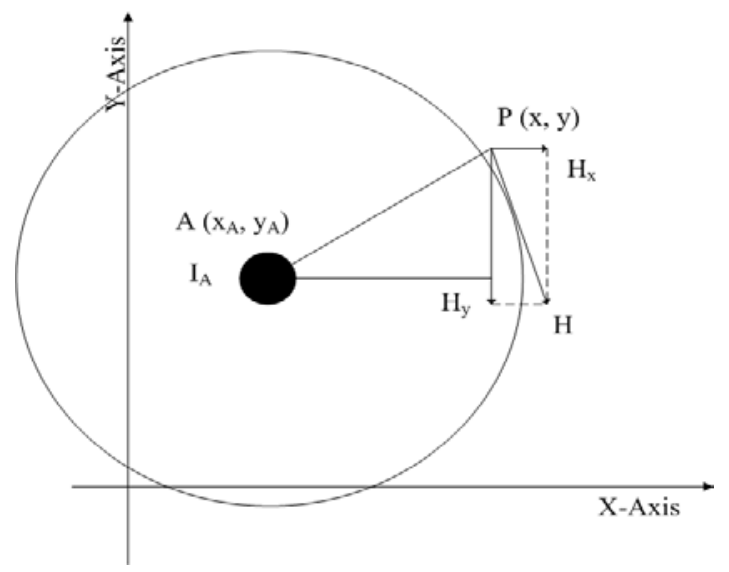

Figure 3.3 Magnetic field lines due to conductor A at any point in space

$$
\overrightarrow{H_{A}}=H_{x, A} \overrightarrow{u_{x}}+H_{y, A} \overrightarrow{u_{y}}
$$


Where,

$\overrightarrow{H_{A}}$ is the magnetic field intensity caused due to conductor $A$ at point $P$.

$H_{x, A}$ and $H_{y, A}$ are the magnitudes of the magnetic field given by equation 3.10 and 3.11 .

$\overrightarrow{u_{x}}$ and $\overrightarrow{u_{y}}$ are the unit vectors along the horizontal and vertical axis.

$$
\begin{aligned}
& H_{x, A}=\frac{I_{A}\left(y-y_{A}\right)}{2 \pi\left[\left(x-x_{A}\right)^{2}+\left(y-y_{A}\right)^{2}\right]} \\
& H_{y, A}=\frac{I_{A}\left(x-x_{A}\right)}{2 \pi\left[\left(x-x_{A}\right)^{2}+\left(y-y_{A}\right)^{2}\right]}
\end{aligned}
$$

Similarly, horizontal and vertical components of magnetic field intensity for conductors B and C could be calculated. Hence, the total horizontal and vertical components $\vec{H}_{x}$ and $\vec{H}_{y}$ due to three conductors are calculated using Equation 3.12 and 3.13. The total magnitude of magnetic field intensity is given by Equation 3.14.

$$
\begin{aligned}
& \overrightarrow{H_{x}}=\overrightarrow{H_{x, A}}+\overrightarrow{H_{x, B}}+\cdots \\
& \overrightarrow{H_{y}}=\overrightarrow{H_{y, A}}+\overrightarrow{H_{y, B}}+\cdots \\
& |H|=\sqrt{\left(H_{x}\right)^{2}+\left(H_{y}\right)^{2}}
\end{aligned}
$$

Magnetic field density across the span is given by equation 3.15

$$
\vec{B}=\mu_{0} \vec{H}
$$

Where, $\mu_{0}=$ permeability of free space.

Using the above equations, the magnetic field was computed for the horizontal example configuration discussed in chapter 2. The magnetic fields for a 
point $1 \mathrm{~m}$ above the ground level with conductor sag of $1.1 \mathrm{~m}$ at mid-span for the example configuration shown in Figure 3.4.

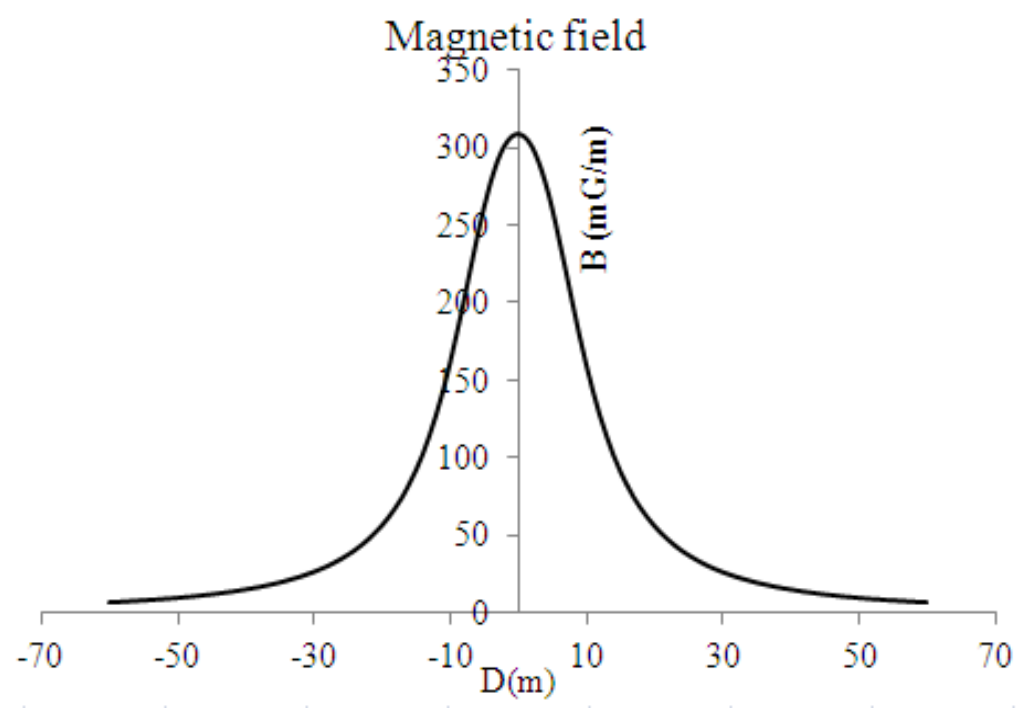

Figure 3.4 Magnetic field measured at $1 \mathrm{~m}$ above the ground level 
Chapter 4. Techniques for increasing power transfer

\subsection{Introduction}

Transmission line design is governed by various factors such as conductor voltage gradient, switching and lightning over voltages, corona and reduced electrical strength due to contamination [7][8]. Transmission structures must be designed such that the phase-to-phase and phase-to-tower clearances are able to withstand the switching and lightning surges, swinging and galloping of the conductors under abnormal weather conditions [7][8]. The National Electrical Safety Code (NESC) standardized the minimum phase-to-phase and phase-to-tower clearances required for safe operations and maintenance [18]. While designing the transmission lines, these clearances are generally higher than the minimum requirement for protection against lightning and switching surges, swinging and galloping of conductors[7][8]. Hence, line compaction could be achieved by using techniques like inter-phase spacers, which controls conductor motion, and line arresters for protection against lightning and switching surges [27].

With the advancement in technology several new types of conductors have been developed. These new conductors called High Temperature Low Sag conductors (HTLS) are able to carry large current with higher thermal and lower sag limits.

In 1970s Barnes and Barthold developed the high phase order system consisting of six, nine or twelve phase instead of the conventional three phase system [28]. A test line was developed in Saratoga, New York as well as a double circuit 
$115 \mathrm{kV}$ line was converted to a $93 \mathrm{kV}$ (line-to-ground) six phase line [29][30].The advantage of high phase order system is that the line-to-line voltage is less than or equal to line-to-ground voltage. This reduces the phase-to-phase and the phase-totower clearance requirements, increasing the possibility of line compaction.

This chapter discusses in detail these three techniques that aid in increasing power transfer capability, relieving congestion in the system and effectively using the right-of-way.

\subsection{Line compaction}

It is known that power transfer capability is inversely proportional to the positive sequence reactance of the line. Equation 2.10 provides the positive sequence reactance of the line, which depends on the self and mutual reactance [7]. For a given line, $X_{s}$ depends on the conductor properties and is constant and $X_{m}$ depends on the inter-phase distance and mutual coupling between the phases. Line compaction reduces the phase-to-phase distance causing higher mutual coupling. This results in higher $X_{m}$, reducing the positive sequence reactance of the line. Hence, the power transfer capability is higher for compact line as compared to conventional uncompact configuration.

In order to understand the effect of line compaction three different tower configurations were studied. The towers include three phase single circuit horizontal, vertical configurations and three phase double circuit vertical configuration. Figure 4.1 shows a typical $230 \mathrm{kV}$ single circuit horizontal, vertical and double circuit vertical tower configurations which were studied [31]. 


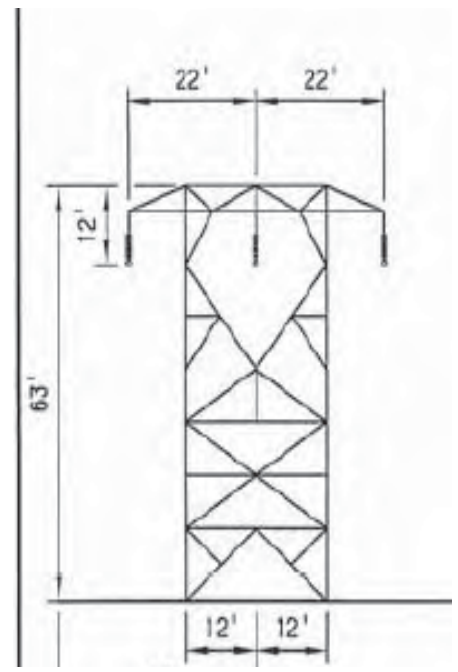

Configuration - 1

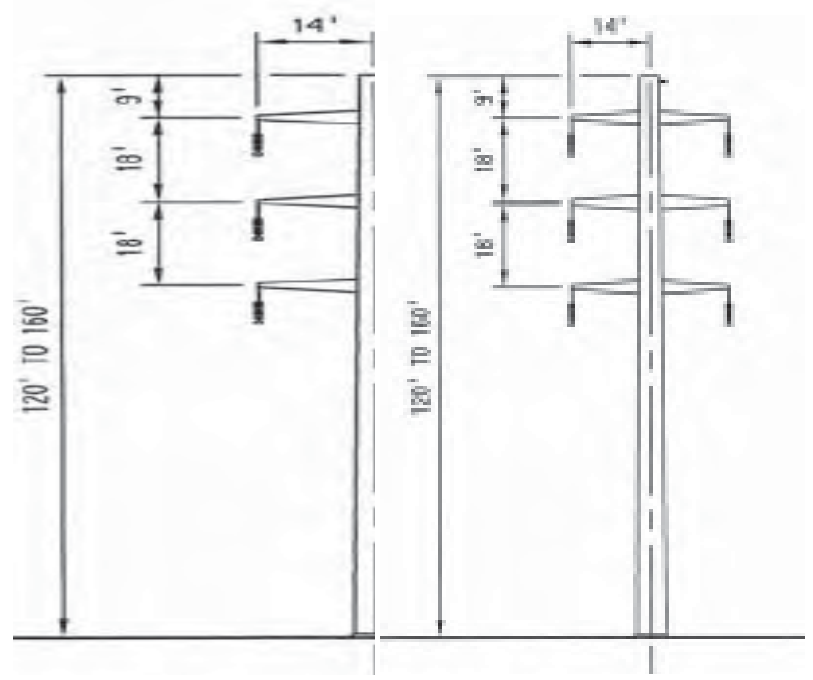

Configuration - 2 Configuration - 3

Figure 4.1Various configurations (230 kV) [31]

Table 4-1 provides detail of various configurations and the comparison between the actual clearances of the tower with the minimum NESC requirement [18]. Since the clearances (phase-to-phase and phase-to-tower) are higher than the NESC requirement, the line is compacted until a NESC criterion is not violated. For example, in configuration - 1, line compaction is carried out such the phaseto-tower clearances is reduced to the minimum requirement of $1.24 \mathrm{~m}$, causing a phase-to-phase clearances of $2.48 \mathrm{~m}$. Figures $4.2,4.3$ and 4.4 indicate the change in positive and zero sequence reactance for all three configurations using the Bluebird conductor. 
Table 4-1 Comparison of clearances with the minimum NESC requirement

\begin{tabular}{|c|c|c|c|c|}
\hline Clearances & $\begin{array}{c}\text { Horizontal } \\
\text { configuration }\end{array}$ & $\begin{array}{c}\text { Vertical con- } \\
\text { figuration }\end{array}$ & $\begin{array}{c}\text { Three phase } \\
\text { double circuit } \\
\text { (Vertical configu- } \\
\text { ration) }\end{array}$ & $\begin{array}{c}\text { Minimum } \\
\text { requirement } \\
\text { as per NESC }\end{array}$ \\
\hline $\begin{array}{c}\text { Phase to } \\
\text { phase (m) }\end{array}$ & 6.70 & 5.48 & 5.48 & 1.6 \\
\hline $\begin{array}{c}\text { Phase to } \\
\text { tower (m) }\end{array}$ & 3.04 & 1.75 & 1.75 & 1.24 \\
\hline $\begin{array}{c}\text { Height of } \\
\text { the lower } \\
\text { conductor } \\
\text { (m) }\end{array}$ & 15.54 & 21.10 & 21.10 & \\
\hline
\end{tabular}

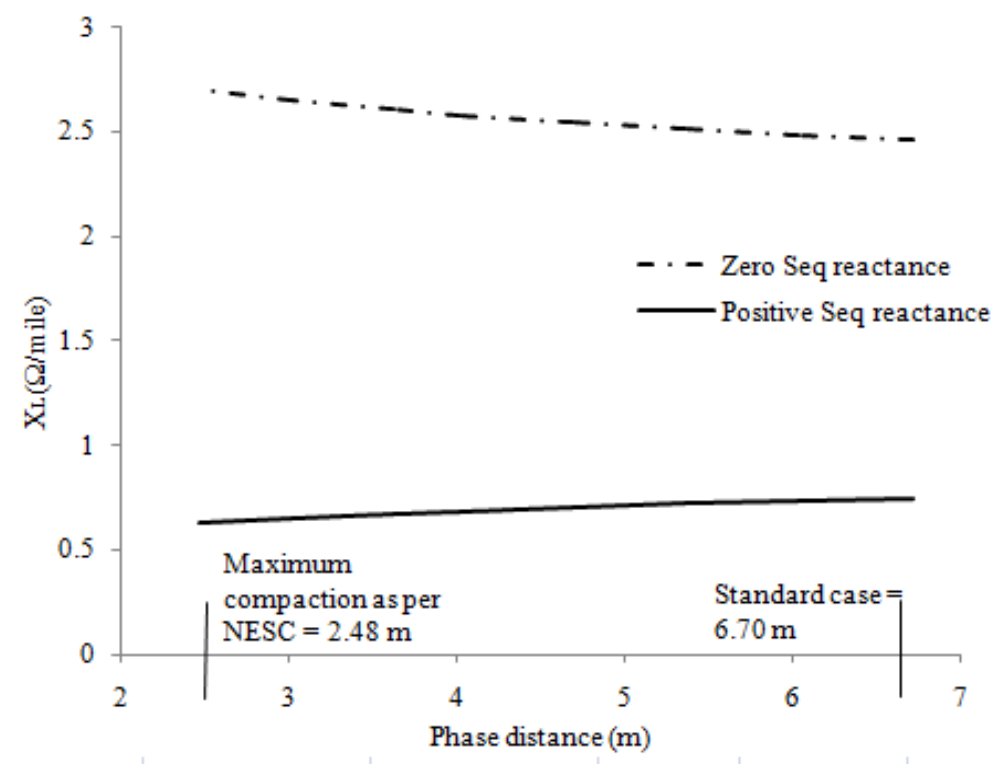

Figure 4.2 Change in reactance for configuration - 1 


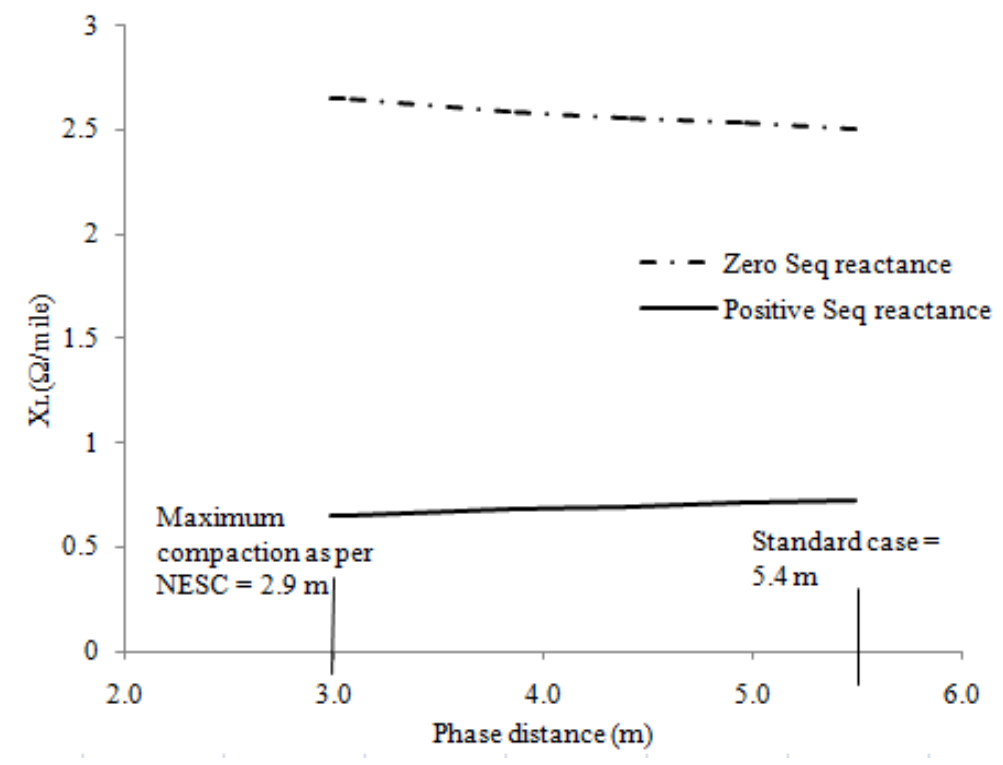

Figure 4.3 Change in reactance for configuration - 2

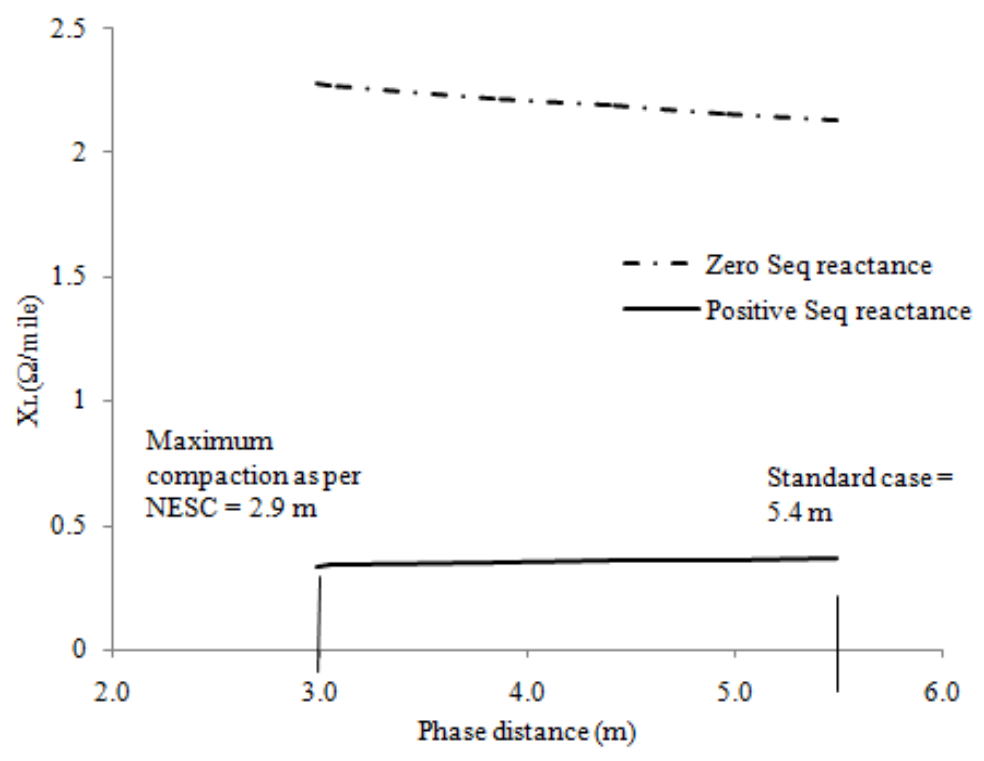

Figure 4.4 Change in reactance for configuration - 3

The results indicate $8-16 \%$ reduction in reactance that increases the power transfer capability of the line.

Another advantage of line compaction is the reduction in electric and magnetic field values at the edge of right of way. As shown in Chapter 3 the elec30 
tric and magnetic field are becoming more stringent. Line compaction reduces the values of electric and magnetic field at edge of right of way. Thus reducing the right of way requirement of the line. Figures 4.5, 4.6 and 4.7 indicate the comparison of electric and magnetic field between standard and compact configurations calculated at $1 \mathrm{~m}$ above the ground level, across the right of way at mid-span, with a sag of $7.4 \mathrm{~m}$.
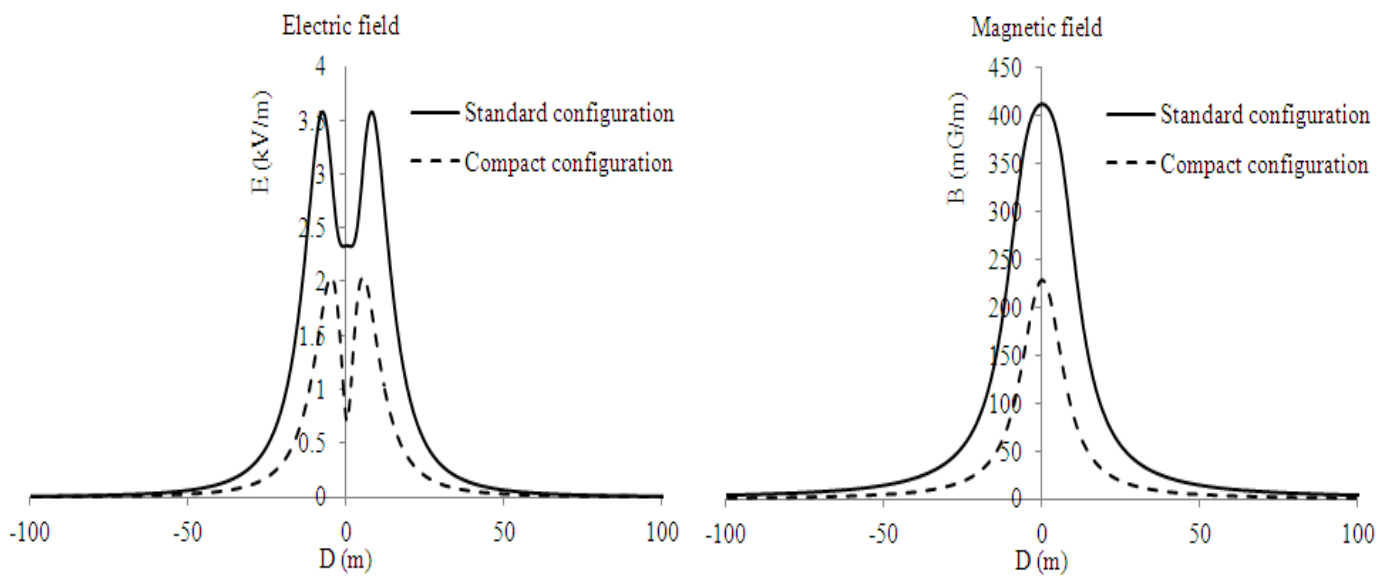

Figure 4.5 Electric and magnetic field plots for configuration - 1

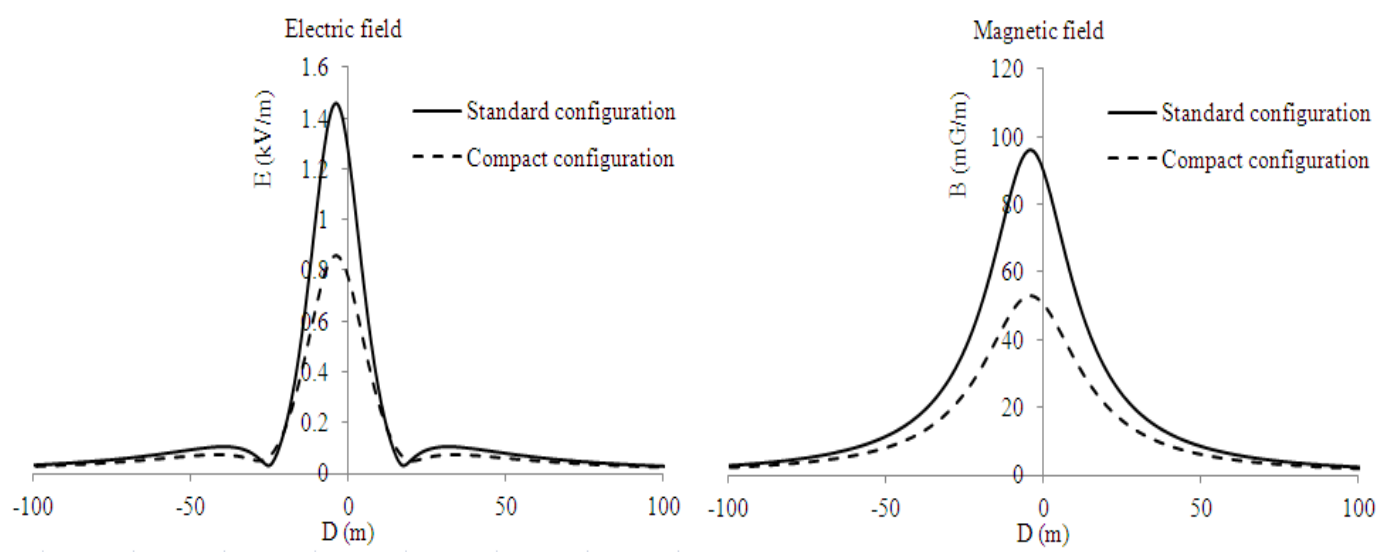

Figure 4.6 Electric and magnetic field plots for configuration - 2 


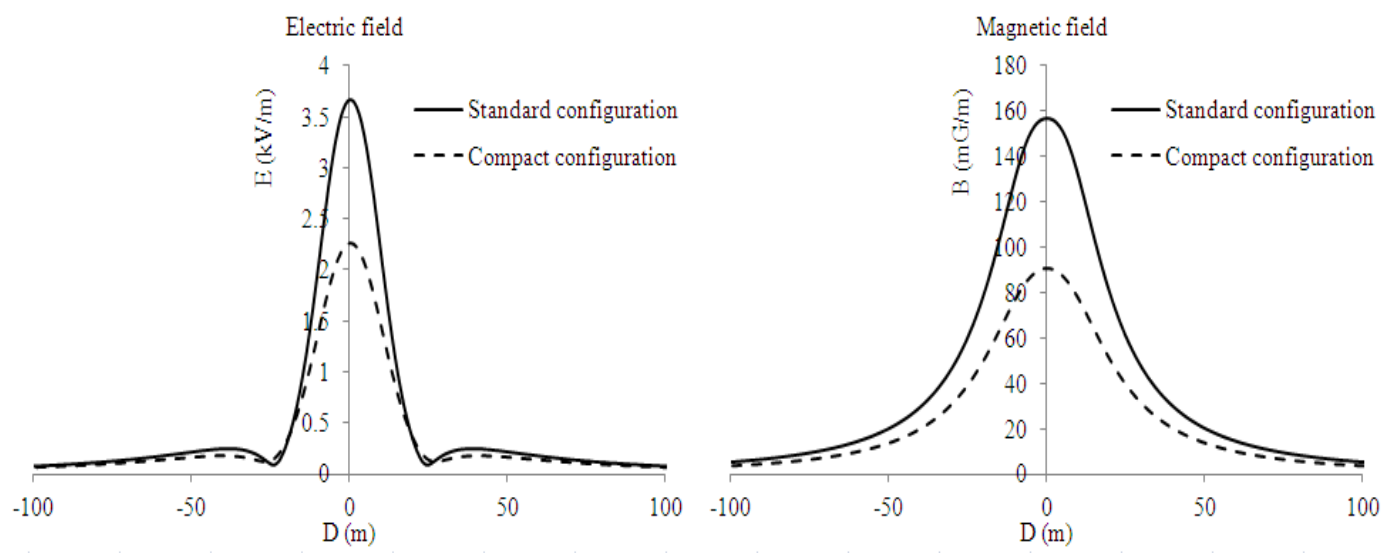

Figure 4.7 Electric and magnetic field plots for configuration - 3

Another important point of interest in compact configurations mentioned above is that even though the phase-to-tower clearance has reached its minimum value as per NESC requirements, the phase-to-phase distance is still higher than the minimum value. Hence, new compaction techniques are developed using inter-phase spacers with composite insulators. For example, configuration - 1 in Figure 4.1, the configuration obtained by compacting it to minimum NESC requirement is shown as the compact configuration - 1a in Figure 4.8. The new compaction technique using inter-phase spacers is shown as the compact configuration - $1 \mathrm{~b}$ and 1c in Figure 4.8. In compact configuration - 1b using inter-phase spacers the phase-to-phase distance is gradually reduced to $1.6 \mathrm{~m}$ at mid-span. While in compact configuration - 1c, the phase-to-phase distance of $1.6 \mathrm{~m}$ was attained closer to the tower and was kept unchanged for the major portion of the line. 


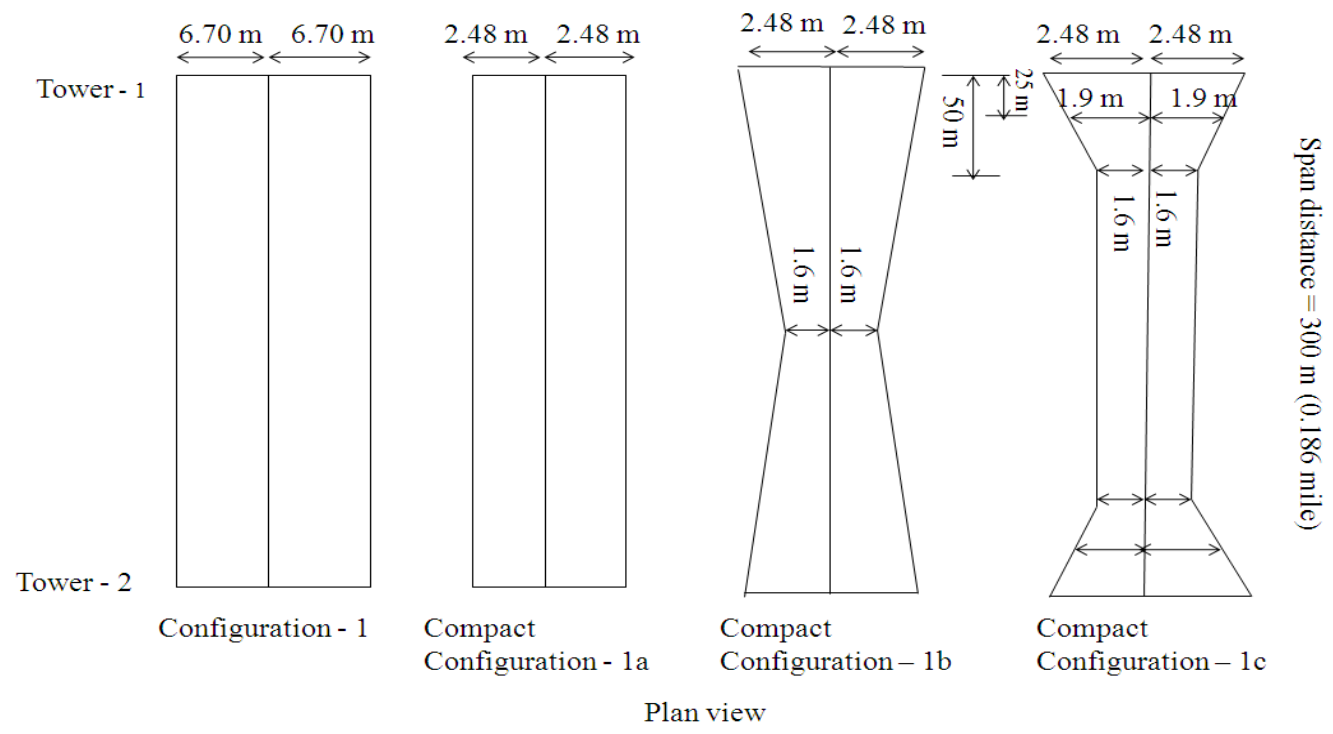

Figure 4.8 Various compact configurations

Figure 4.9 shows the comparative line reactance for all four configurations $(1,1 \mathrm{a}$, 1b and 1c) over the span of the line. The net reactance of the line over its span was obtained by integrating the areas under the line reactance curves.

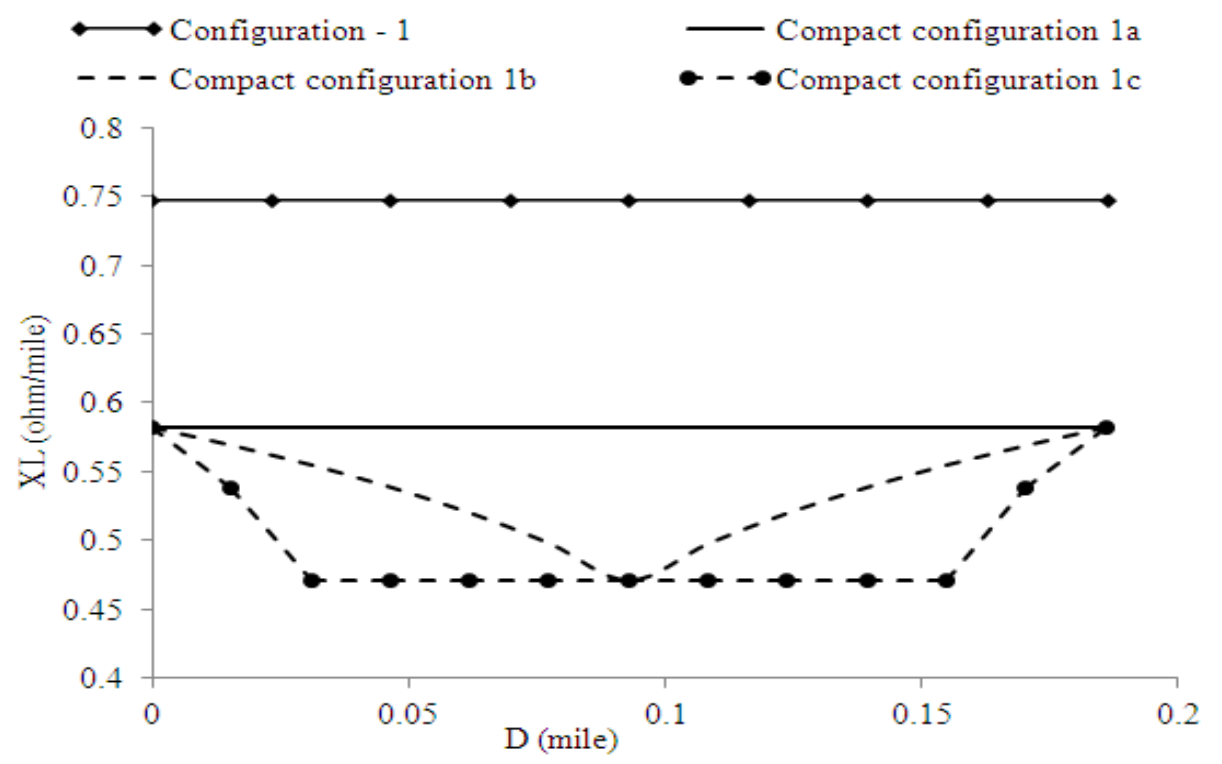

Figure 4.9 Change in reactance for various horizontal compact configurations 
Similarly compaction was carried out for configuration 2 and 3 and Figures 4.10 and 4.11 show the comparative line reactance over the span of line.

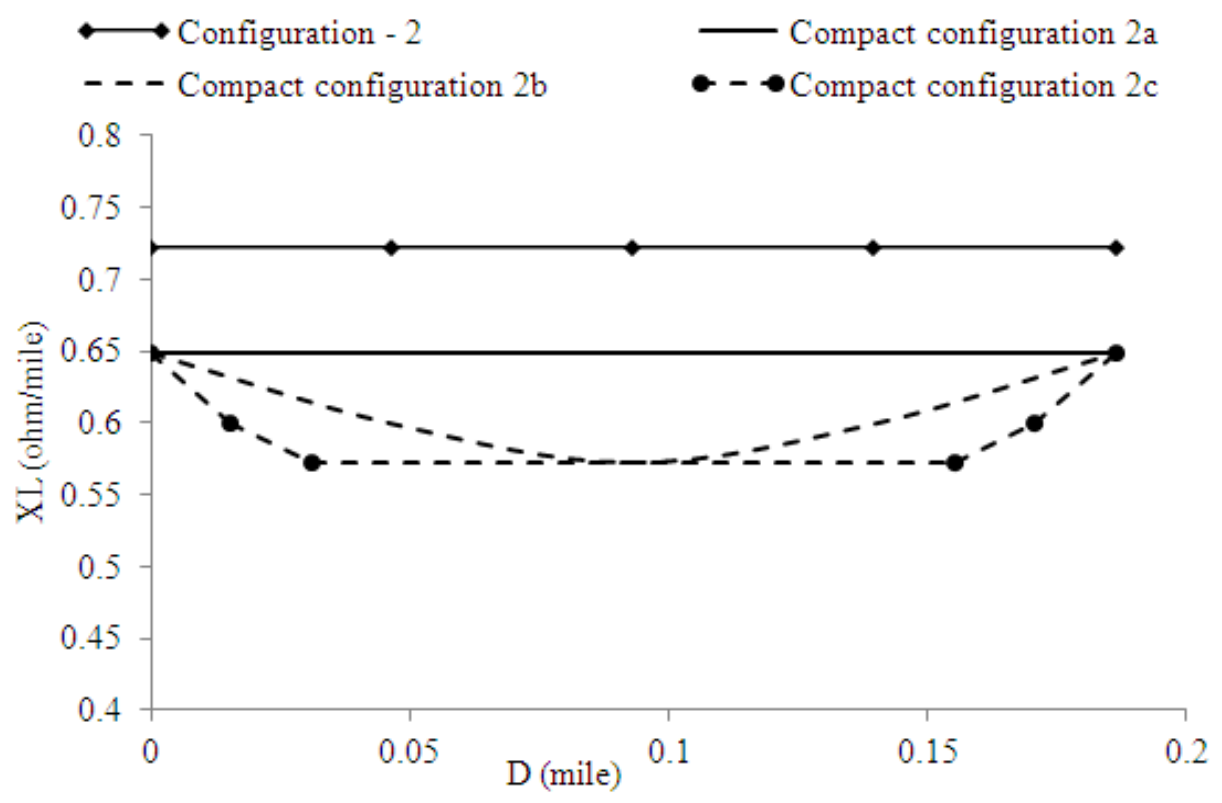

Figure 4.10 Change in reactance for various vertical compact configurations

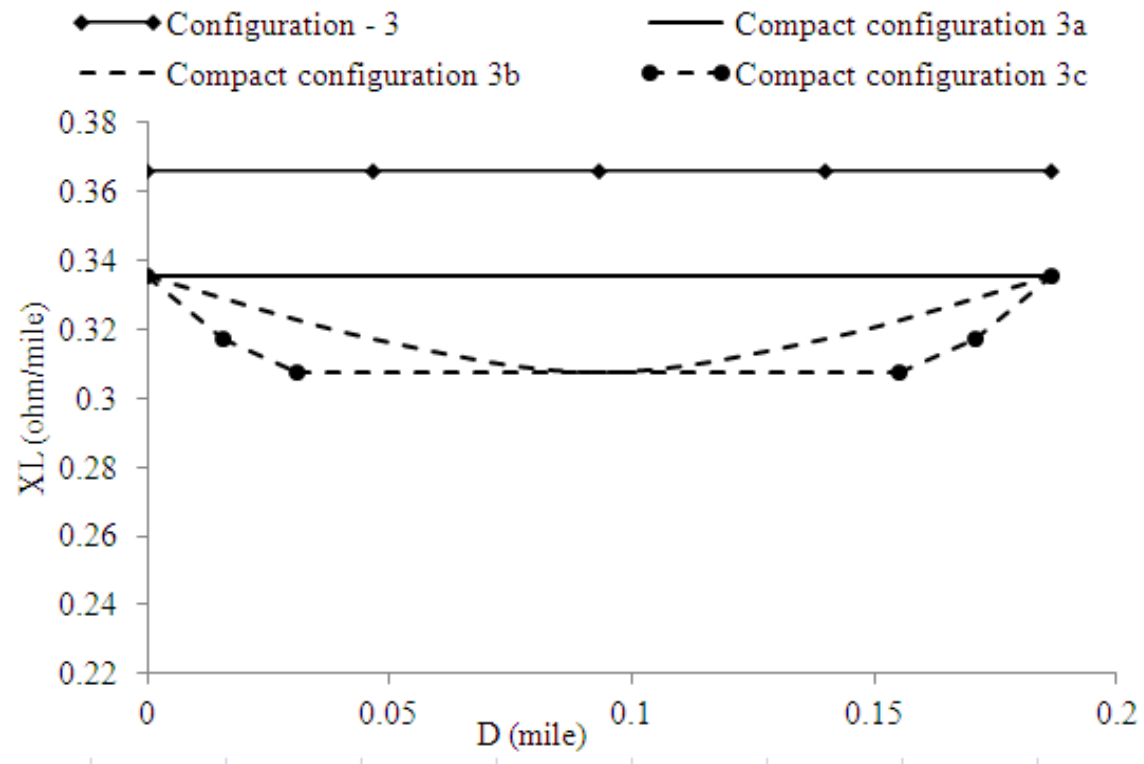

Figure 4.11 Change in reactance for various double circuit vertical compact configurations 
It was observed that $15-35 \%$ reduction in line reactance was achieved, when compared to standard configurations. The maximum reduction was obtained by compaction with inter - phase spacers. Theoretically, this would result in increasing the power transfer capability in the range of $17-53 \%$. However, as discussed in Chapter 2 various limitations affects the power transfer capability in the larger interconnected system. These factors affect the actual power transfer capability achieved in the system.

As shown in Figure 4.5, line compaction aides in reduction of electric and magnetic field at the edge of right of way. Figure 4.12 indicates the comparison of electric and magnetic field using configuration $1,1 \mathrm{a}, 1 \mathrm{~b}$ and $1 \mathrm{c}$.

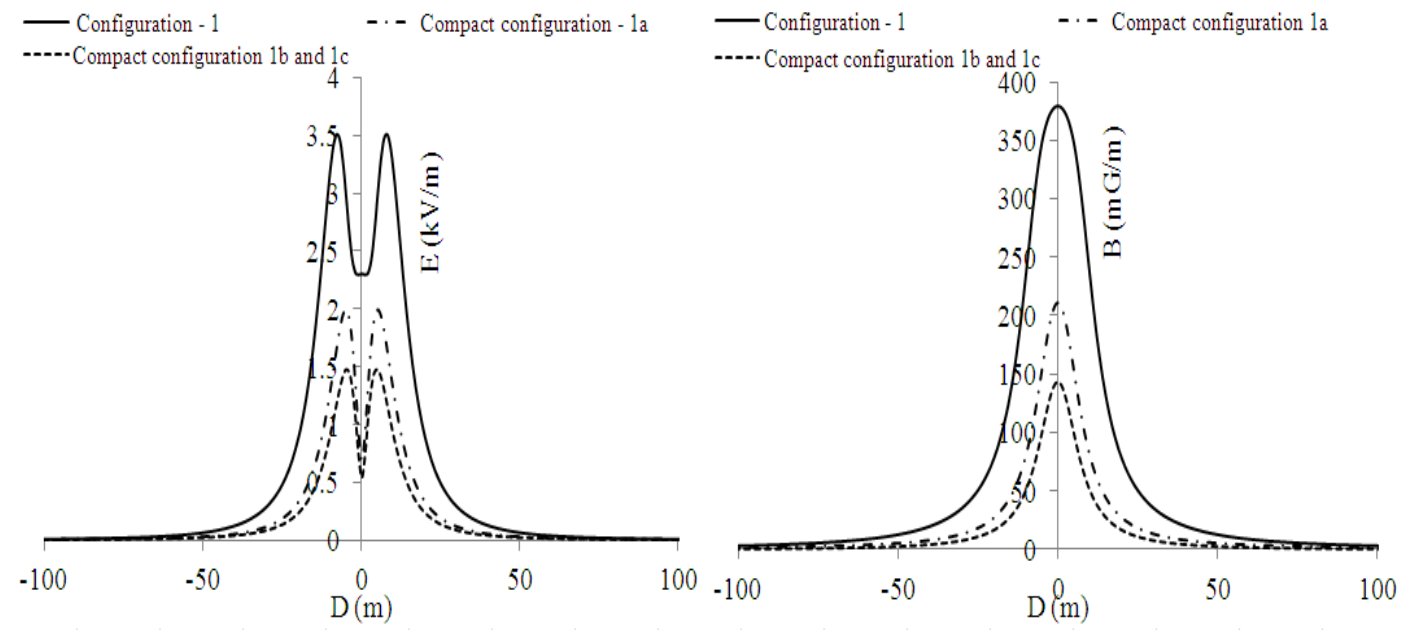

Figure 4.12 Electric and magnetic field comparisons

The other advantages of line compaction are:

- Increasing the peak of power angle curve causing increase in system stability.

- Improved voltage regulation and stability. 


\subsection{High temperature low sag conductors (HTLS)}

Present Aluminum Conductor Steel Reinforced (ACSR) conductors are capable of carrying rated capacity at $75^{\circ} \mathrm{C}\left(167^{\circ} \mathrm{F}\right)$ [19][32]. However, due to high atmospheric temperature and thermal heating of conductors the current carrying capacity is limited. Moreover, excessive heating causes elongation of conductors which increases sagging. These may jeopardize the safe and reliable operation of the line. To overcome these issues of thermal and sag limits, new types of conductors have been developed that can sustain high current carrying capacity at higher temperature range with lower sagging. These conductors could be used in lines which are thermal and sag limited. Different types of HTLS conductors are developed like Aluminum Conductor Composite Core (ACCC), Aluminum Conductor Steel Supported (ACSS), Aluminum Conductor Composite Reinforced (ACCR) and Aluminum Conductor Alloy Reinforced (ACAR). Table 4-2 shows the comparison of various HTLS conductors with conventional ACSR conductors for Drake type conductor [32]. 
Table 4-2 Comparison of HTLS conductor with ACSR conductor (Drake)

\begin{tabular}{|c|c|c|c|c|}
\hline \multirow{2}{*}{$\begin{array}{c}\text { Conductor } \\
\text { type }\end{array}$} & Diameter & $\begin{array}{c}\text { Resistance } \\
\left(\text { AC@ } @ 75^{\circ} \mathrm{C}\right)\end{array}$ & $\begin{array}{c}\mathrm{X}_{1} \text { (Induc- } \\
\text { tive reac- } \\
(\Omega / \mathrm{mile})\end{array}$ & $\begin{array}{c}\text { Current capacity } \\
\text { tance @ } 1 \mathrm{ft})\end{array}$ \\
\hline ACSR & 1.108 & 0.1389 & 0.399 & $900 @ 75^{\circ} \mathrm{C}$ \\
\hline ACCC & 1.11 & 0.1085 & 0.401 & $1695 @ 180^{\circ} \mathrm{C}$ \\
\hline ACCR & 1.128 & 0.1300 & 0.3999 & $1813 @ 210^{\circ} \mathrm{C}$ \\
\hline ACSS & 1.108 & 0.1368 & 0.4012 & $1697 @ 200^{\circ} \mathrm{C}$ \\
\hline ACAR & 1.108 & 0.1261 & 0.405 & \\
\hline
\end{tabular}

It can be seen that even though the mechanical characteristic of various HTLS conductors are similar with ACSR conductor the current carrying capacity and temperature limits are higher. Hence, there is a significant amount of increase in power transfer with the same positive sequence reactance.

\subsection{High phase (six phase) order system}

Barnes and Barthold pioneered the development of high phase order system to satisfy future load demand and effectively utilizing the right of way [28]. As mentioned in Section 4.1 the line to line voltage is less than or equal to line to ground voltage. Table 4-3 indicates the relationship between line to line and line to ground voltage for high phase order system [30]. 
Table 4-3 Relationship between line to line and line to ground voltage in high phase order system

\begin{tabular}{|c|c|}
\hline Three phase system & $V_{L L}=V_{L G} * \sqrt{3}$ \\
\hline Six phase system & $V_{L L}=V_{L G}$ \\
\hline Twelve phase system & $V_{L L}=0.517 * V_{L G}$ \\
\hline
\end{tabular}

In this study, improvement in present infrastructure was considered. Hence, a conversion of three phase double circuit to six phase single circuit was studied as it would not require any additional right of way requirement. In order to achieve the conversion of three phase circuit to six phase circuit various techniques were available. They are: 1) Three phase to six phase transformer 2) Power electronics convertor [33].

Power transfer capability is an important factor while comparing a three phase double circuit to a six phase circuit. Equation 4.1 indicates the power transfer capability for a $n$ - phase system with line to ground voltage.

$$
P=\frac{n V_{L-G}{ }^{2}}{Z_{s}}
$$

Hence, keeping the same line to ground voltage the power transfer capability of the line is inversely proportional to the surge impedance. Surge impedance for a three phase circuit is studied in Section 2.2. Similar procedure could be applied for six phase system resulting in a 6 X 6 impedance and capacitance matrix corresponding to six sequences of a six phase system. Considering the same 132.8 
$\mathrm{kV}$ (line to ground voltage) three phase double circuit (Configuration - 3) as in Section 4.2 having the surge impedance of $180.28 \Omega$ when converting it to a $132.8 \mathrm{kV}$ six phase single circuit becomes $352.18 \Omega$. Hence the power transfer capability of a $132.8 \mathrm{kV}$ three phase double circuit is nearly equal to a $132.8 \mathrm{kV}$ six phase single circuit. However, upgrading the insulator string for $230 \mathrm{kV}$ (line to ground voltage) a six phase system has a power transfer capability of 1.732 times as compared to three phase double circuit. Based on this, using Falcon conductor having a current carrying capacity of 1000 A. Figure 4.13 compares the line-to-line voltage required to transfer equal amount of power in a three phase double circuit to a six phase single circuit.

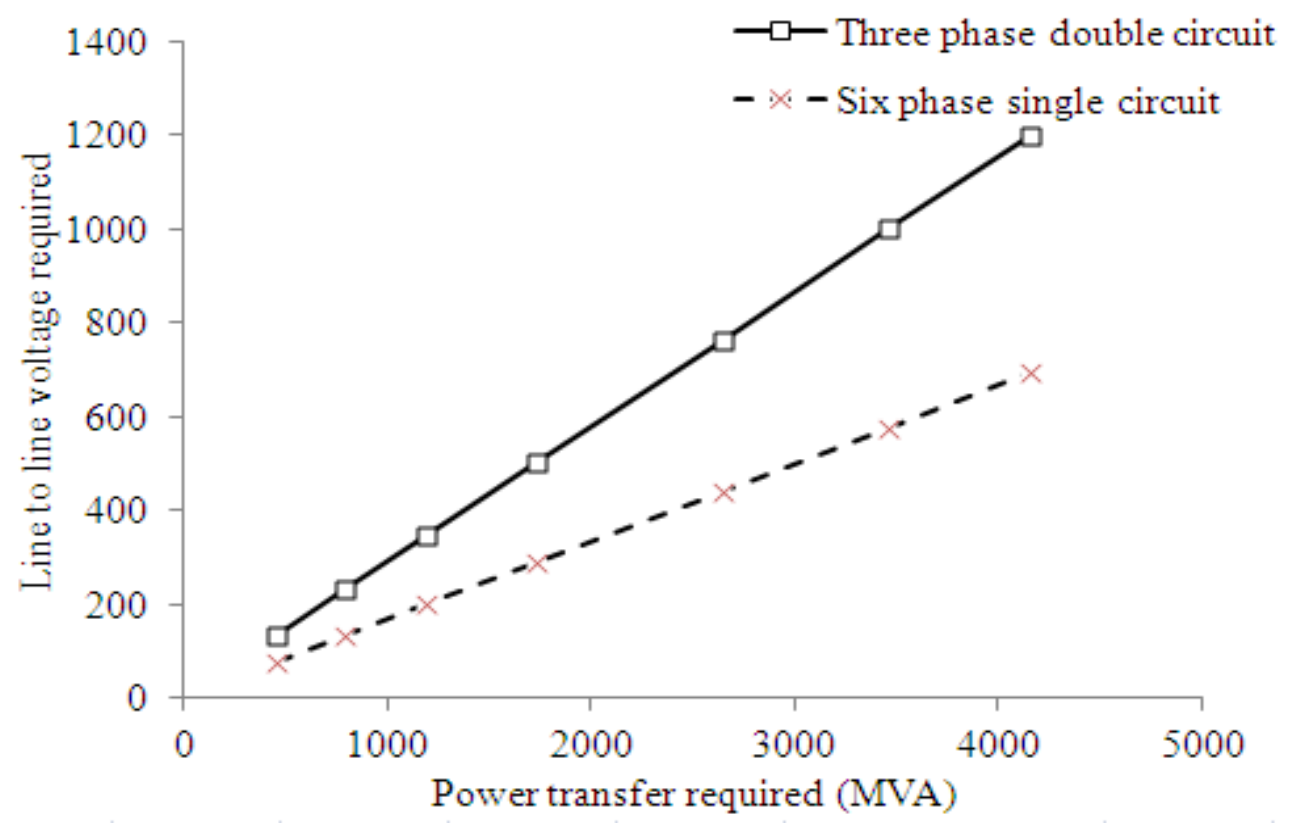

Figure 4.13 Voltage requirement for three phase double circuit and six phase single circuit for same amount of power transfer 
From Figure 4.13 it is clear that in order to transfer equal amount of power higher voltages are required in case of three phase double circuit as compared to six phase single circuit. Thus, reduces the right of way requirement in six phase lines as compared to a three phase lines. 


\section{Chapter $5 . \quad$ Validation of techniques}

\subsection{Objective and description}

The objective of this chapter is to implement the techniques discussed in Chapter 4. The IEEE 9 and 118 bus test systems are used to validate the results. An IEEE 9 bus test system representing three areas system is shown in Figure 5.1. It consists of three generating stations at buses 1, 2 and 3 and loads at buses 5, 6 and 8 . The line MVA ratings are shown in Table 5-1. Further details regarding the generator, transformer and line parameters can be found in [20][34]. The study was carried out in Power World.

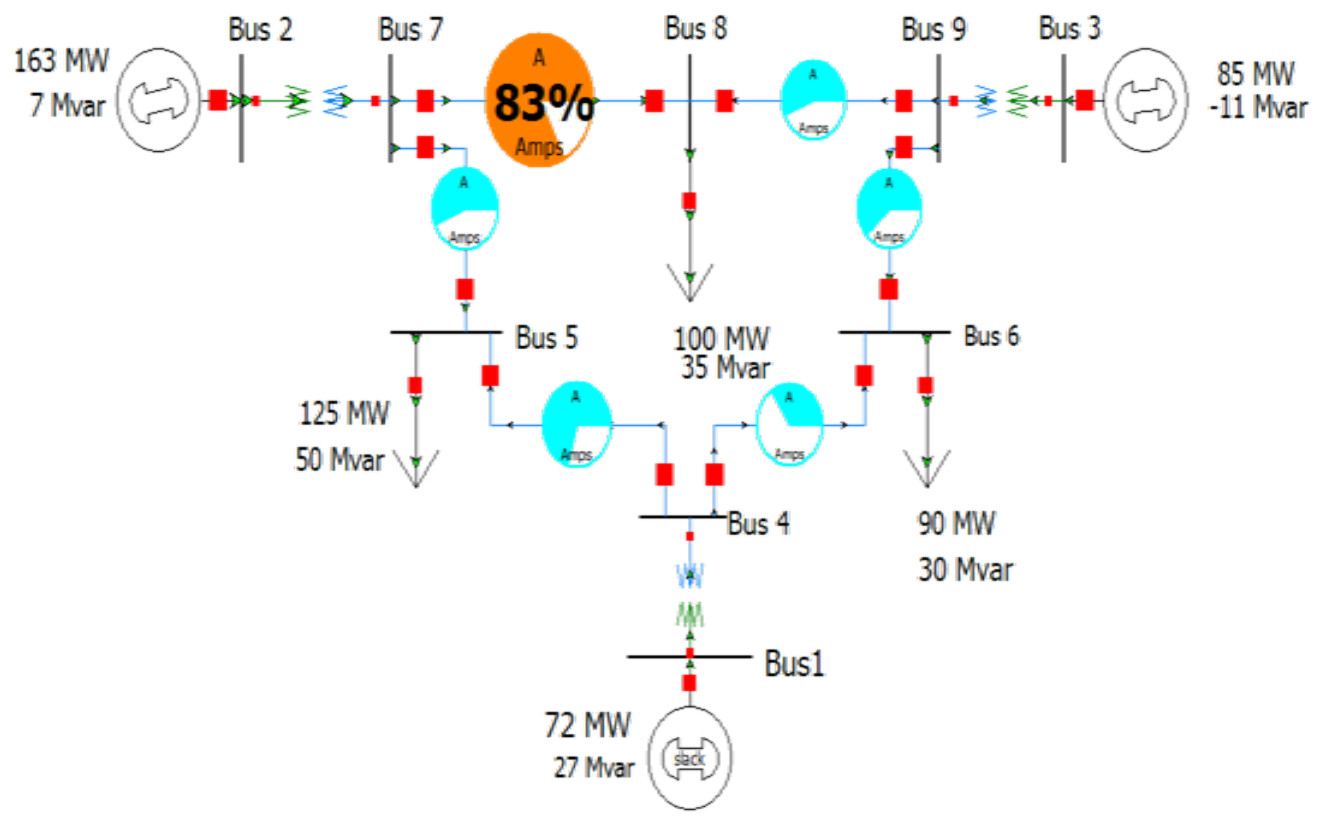

Figure 5.1 Nine bus test system 
Table 5-1 Line limits for nine bus test system

\begin{tabular}{|c|c|}
\hline Line no. & Line ratings (MVA) \\
\hline $7-8$ & 90 \\
\hline $7-5$ & 150 \\
\hline $5-4$ & 80 \\
\hline $4-6$ & 100 \\
\hline $6-9$ & 100 \\
\hline $8-9$ & 60 \\
\hline
\end{tabular}

\subsection{Base case}

Figure 5.1 indicates the base case. The pie - chart on the top of transmission line represents the percentage of the line MVA loading. Power flow results were that the line connecting bus 7 and 8 was the most congested line of the system.

\subsection{Case - 1: Line compaction}

The line compaction technique mentioned in Section 4.2 was applied to all transmission lines in the system. It is assumed that the line compaction technique reduces $30 \%$ of line reactance. Table 5 -2 shows various cases of line compaction, affecting the power flow on line 7- 8. 
Table 5-2 Effect of compaction techniques on congested line 7 - 8

\begin{tabular}{|c|c|c|}
\hline Case no. & $\begin{array}{c}\text { Compaction technique } \\
\text { applied to line }\end{array}$ & $\begin{array}{c}\text { Change in power flow on line 7-8 } \\
\text { (as percentage of line rating) }\end{array}$ \\
\hline $1 \mathrm{a}$ & $7-8$ & $+2 \%$ \\
\hline $1 \mathrm{~b}$ & $7-5$ & $-7 \%$ \\
\hline $1 \mathrm{c}$ & $8-9$ & $+1 \%$ \\
\hline $1 \mathrm{~d}$ & $5-4$ & $+5 \%$ \\
\hline $1 \mathrm{e}$ & $9-6$ & $-2 \%$ \\
\hline $1 \mathrm{f}$ & $6-4$ & \\
\hline
\end{tabular}

It was interesting to note that if the line compaction technique was applied to the congested line (Case 1a), it worsened the situation. To ease the congestion, the compaction technique should be applied to the neighboring lines, as depicted in Case 1b and 1c.

\subsection{Case - 2: HTLS conductor on line $7-8$}

The existing ACSR conductor on line 7 - 8 was replaced with the new HTLS conductor explained in Section 4.3. The rating of the new line was increased by 90 MVA and the corresponding loading was $41 \%$. This eliminated the line congestion and enhanced the overall power transfer capability of the system. Further increase in system load resulted in congestion on other lines. Table 5-3 lists the most congested lines due to increase in load at various buses. 
Table 5-3 Impact of load increment on line congestion

\begin{tabular}{|c|c|c|c|c|}
\hline Case & $\begin{array}{c}\text { Bus num- } \\
\text { ber }\end{array}$ & $\begin{array}{c}\text { Increase in } \\
\text { load } \\
(\mathrm{MW})\end{array}$ & Congested line & $\begin{array}{c}\text { Line Flow } \\
\text { (as percentage of } \\
\text { line rating) }\end{array}$ \\
\hline $2 \mathrm{a}$ & 5 & 50 & $5-4$ & $117 \%$ \\
\hline $2 \mathrm{~b}$ & 8 & 50 & $5-4$ & $93 \%$ \\
\cline { 4 - 5 } & & & $8-9$ & $88 \%$ \\
\hline $\mathrm{n}$ & 6 & 60 & $4-6$ & $84 \%$ \\
\cline { 4 - 5 } & \multirow{2}{*}{6} & & $5-4$ & $76 \%$ \\
\hline
\end{tabular}

5.5 Case -3 : Converting line $7-8$ to high phase order system (six phase)

The study was carried out by converting line $7-8$ to a six-phase line and the impact on congestion was investigated. The line to ground voltage of sixphase line was kept at $132 \mathrm{kV}$, equal to the line to ground voltage of a three-phase double circuit line. The study was carried out by converting six-phase impedance to equivalent three-phase single circuit impedance. Converting the line to sixphase system increased the capacity to 180 MVA. The results indicated that the power flow on line $7-8$ was reduced to $44 \%$ from $83 \%$. Table $5-4$ indicates the congested line in the system if the load is increased. 
Table 5-4 Impact of load increment on line congestion

\begin{tabular}{|c|c|c|c|c|}
\hline Case & $\begin{array}{c}\text { Bus num- } \\
\text { ber }\end{array}$ & $\begin{array}{c}\text { Increase in } \\
\text { load } \\
(\mathrm{MW})\end{array}$ & Congested line & $\begin{array}{c}\text { Percentage flow of } \\
\text { maximum rating }\end{array}$ \\
\hline 1 & 5 & 50 & $5-4$ & $121 \%$ \\
\hline 2 & 8 & 50 & $5-4$ & $98 \%$ \\
\hline 3 & 6 & 60 & $4-6$ & $79.7 \%$ \\
\cline { 4 - 5 } & & & $5-4$ & $79.5 \%$ \\
\hline
\end{tabular}

Similar results were obtained when converting line $7-8$ to a three-phase double circuit line. Hence, maintaining the same line to ground voltage does not increase the power transfer capability of the line. However, upgrading it to 230 $\mathrm{kV}$ six-phase line enables it to carry power equivalent to a $400 \mathrm{kV}$ three-phase line.

5.6 Case -4 : Transient stability analysis

A transient stability analysis was performed on the system with and without line compaction. The generators were modeled as GENCLS and details of the parameters are shown in Appendix - B. Table 5-5 shows the critical clearing time (CCT) for both the uncompact and compact cases when there was a three-phase fault on various transmission lines. The table indicates the increase in critical clearing time because of line compaction. 


\begin{tabular}{|c|c|c|c|c|c|c|}
\hline 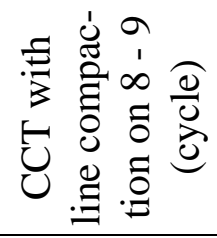 & $\underset{ت}{ \pm}$ & 거 & 그 & $\underline{\sigma}$ & $\infty$ & 그 \\
\hline 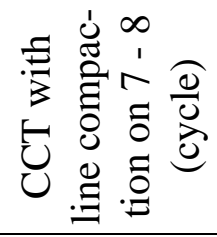 & $\underset{ت}{ \pm}$ & 거 & $\exists$ & 당 & $\infty$ & 二 \\
\hline 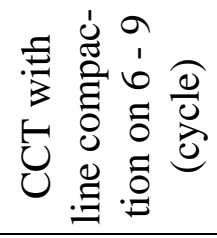 & $\underset{ت}{ \pm}$ & 거 & 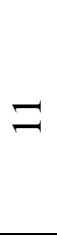 & $\widehat{\approx}$ & $\infty$ & $\underset{-1}{\simeq}$ \\
\hline 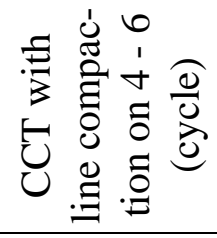 & $\underset{二}{ \pm}$ & 걱 & 二 & $\underline{-1}$ & $\infty$ & 二 \\
\hline 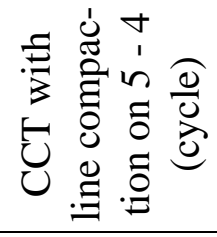 & $\stackrel{m}{\sim}$ & 걱 & ન & $\underline{-}$ & $\infty$ & 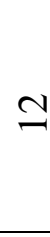 \\
\hline 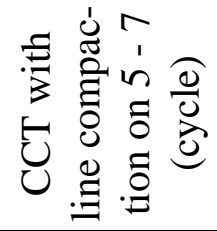 & $a$ & 거 & ન & $\stackrel{\infty}{-1}$ & $\sigma$ & $\widetilde{\gamma}$ \\
\hline 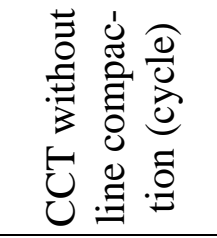 & 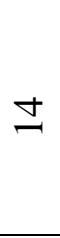 & ન & ન & $\underline{-1}$ & $\infty$ & 二 \\
\hline 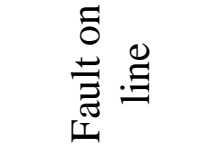 & 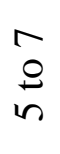 & $\begin{array}{l}+ \\
\stackrel{+}{0} \\
\text { ப }\end{array}$ & $\begin{array}{l}0 \\
\stackrel{0}{+} \\
\forall\end{array}$ & $\begin{array}{l}\sigma \\
\stackrel{9}{0} \\
0\end{array}$ & $\begin{array}{l}\infty \\
\stackrel{0}{1} \\
\end{array}$ & $\underset{\infty}{\infty} \underset{0}{\infty}$ \\
\hline
\end{tabular}


5.7 Objective and description of the 118 bus test system

As discussed in the above sections application of various techniques for increasing power transfer capability results in reducing congestion of the system. The objective of this study was to illustrate few cases explaining the application of these techniques in transmission planning and system improvement.

In order to study the application of techniques in planning and system improvement, an IEEE 118 bus test system was used [34][35]. A detail of the system is available in Appendix - C. The test system was divided into three zones as shown in Figure 5.2 [35]. Zone - 1 is the area of study consisting of 53 generators, 63 transmission lines and 91 loads. Figure 5.3 indicates the congestion on the lines in 118 bus system. The test system used is not $N-1$ contingency satisfied. $N$ - 1 contingency is a NERC requirement in which a system should remain stable even if a single element is lost in the electric grid. In this study, loss of transmission line was considered.

Table C - 3 in Appendix - C indicates the lists of contingency achieved when a transmission line was lost in the system. The techniques studied in Chapter 4 are applied on the system in order to make it $N-1$ satisfied. 


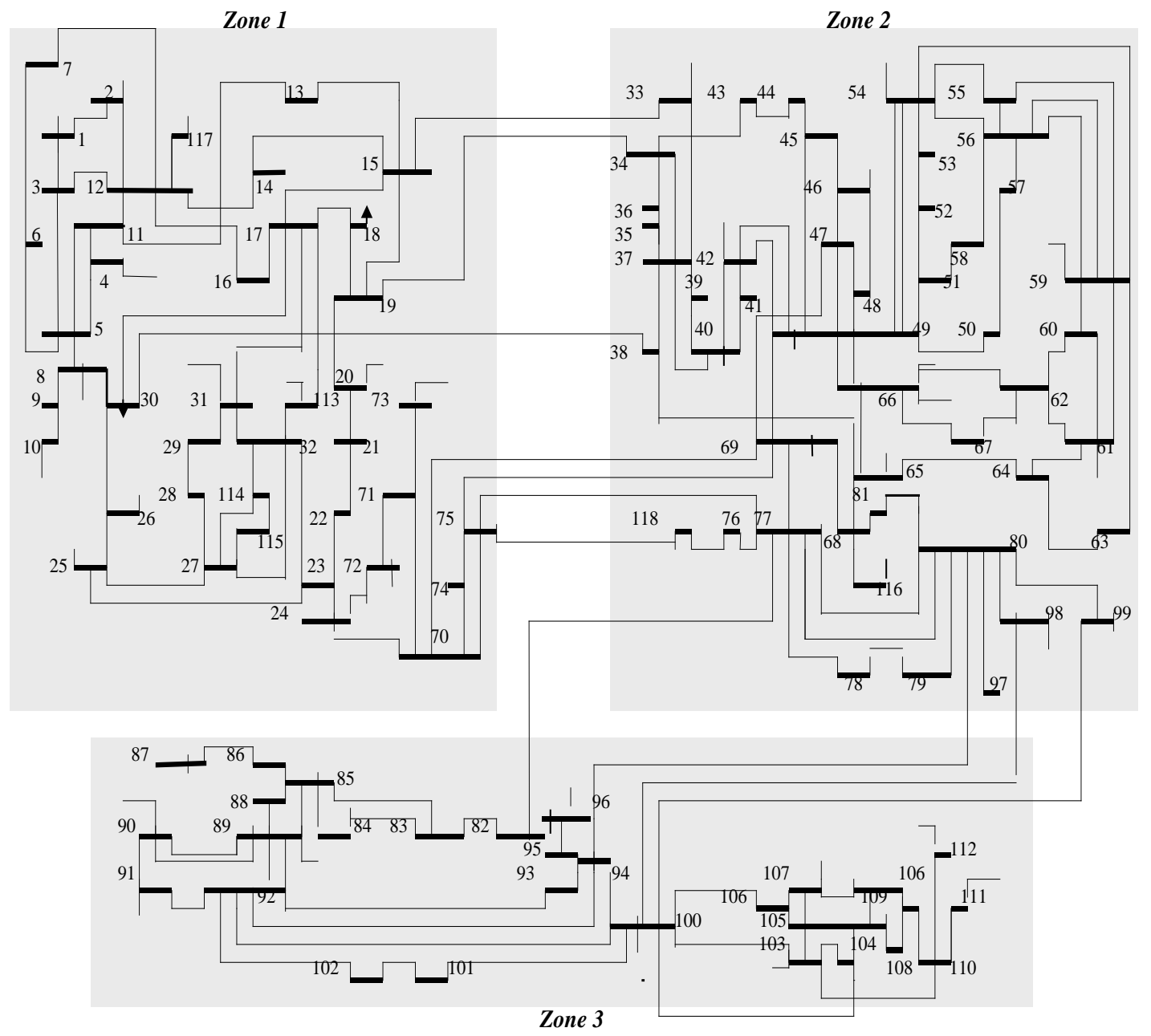

Figure 5.2118 bus test system [35] 


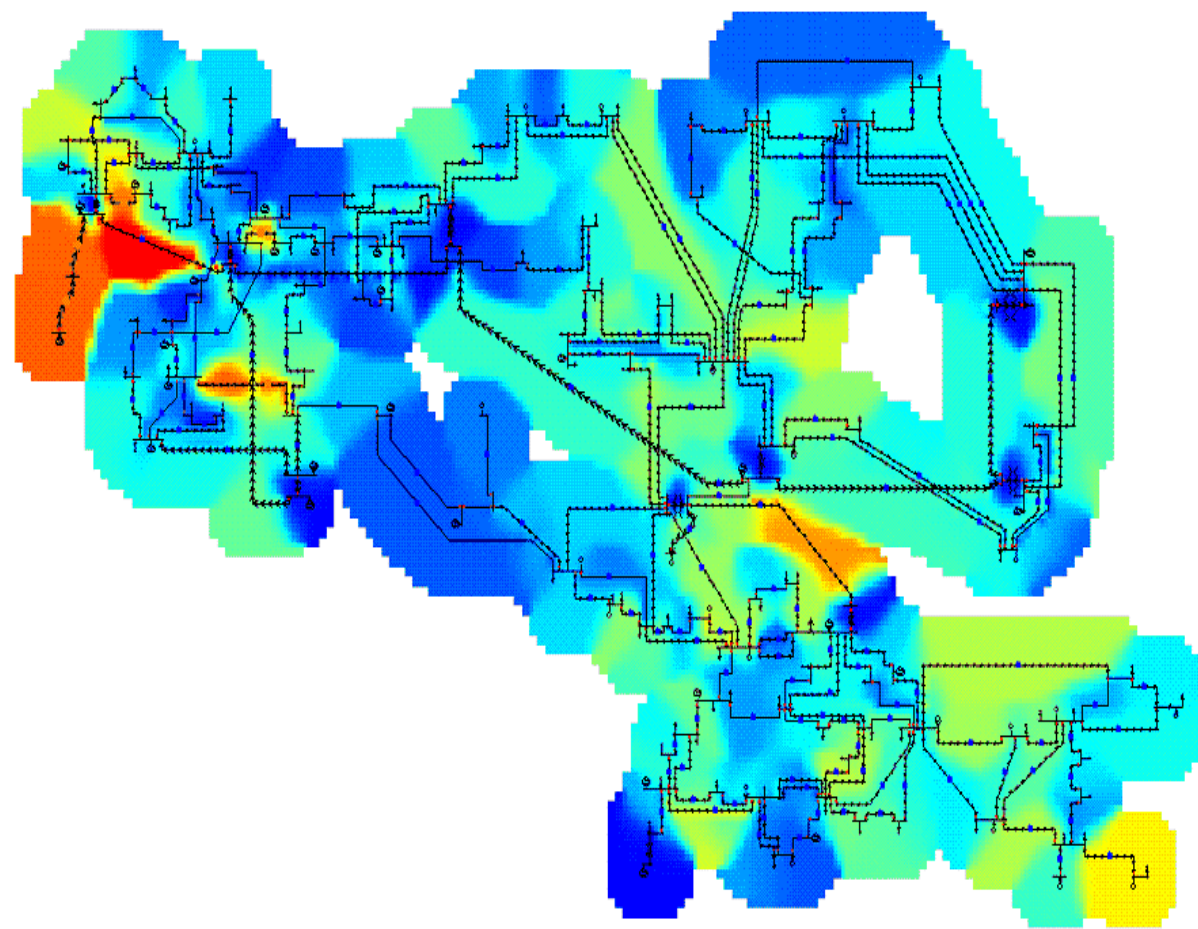

Figure 5.3 Line limit monitoring of IEEE 118 bus test system

\subsection{Case - 5: Line compaction}

During normal operating conditions, a few of the congested lines were 8 30 and 23- 32 with loading of 99\% and 91\% respectively. As seen in Appendix B line 23 - 32 violates 9 contingency. The maximum flow on line $23-32$ is $163 \%$ during contingency. Line compaction technique was used on lines 20 - 21, 21- 22, 22- 23, 26- 30 and 17 - 31 reduced the reactance by 30\%. As a result of line compaction the normal power flow on lines 8 - 30 and 23 - 32 were reduced to $96 \%$ and $82 \%$ respectively. The maximum flow on line 23 - 32 was reduced to $145 \%$ during contingency. 


\subsection{Case - 6: Application of HTLS conductors}

Few lines like 23 - 24, 17 - 18 and 5 - 11 were thermally limited lines having a power flow of $19 \%, 83 \%$ and $78 \%$ respectively. The maximum flow passing through the lines during various contingencies are 115\%,130\% and 130\% respectively. In order to increase the power transfer capability on these lines HTLS conductors can be used. 
Chapter 6. Conclusions and future work

\subsection{Conclusions}

It has been shown that various techniques applied on the test system have improved the power transfer capability and reduced congestion on the system. The following results were obtained from the test systems.

- Line compaction helps in the reduction of line reactance. A 30\% line compaction is possible aiding in increasing power transfer capability and reducing congestion on various lines in the system. This helps in effectively using the existing right of way and satisfying a portion of future load demand. The other advantages of line compaction is the reduction in electric and magnetic field values at the edge of right of way required and could be installed in areas requiring stringent electric and magnetic field restrictions.

- Replacing the present ACSR conductor with the new HTLS conductors on a thermally limited transmission line increases the power transfer capability of the system. The advantage of HTLS conductors over ACSR conductors includes similar line impedance, mechanical properties, better thermal capability and lower sag. As seen in Case -2 in Chapter - 4, for system that make use of HTLS conductors, an increase in load results in the second most congested

line becoming the most congested line of the system. The disadvantage of HTLS conductors is their price being much higher than the present ACSR conductors. 
- High phase (6 phase) order system was studied and it has been found that for the same line to ground voltage the power transfer capability of a three phase double circuit is nearly equal to six phase single circuit. Moreover, the voltage requirement for equal amount of power transfer is lower in a six-phase circuit as compared to a three-phase circuit. This aids in reducing the right of way requirement and increases line compaction. Since the voltage in a six-phase circuit is lower than three-phase, the electric field is lower at the edge of right of way.

\subsection{Future work}

This thesis focuses on techniques for increasing the power transfer capability of the system using the existing right of way. Further studies are required for implementing these techniques on the existing electric grid.

- Line compaction reduces the phase-to-phase and phase-to-tower distance. This might result in the phase to phase and phase to tower flash over during lightning and switching surges. Hence studies and tests are required to verify the Basic insulation Impulse Level (BIL) and Basic Switching insulation Level (BSL) for the compacted transmission line. Lightning arresters installed on transmission towers could aide in maintaining the BIL and BSL of the line.

- Inter-phase spacers made of composite insulators are used in line compaction. Effects of contamination caused due to pollution, water, ice and other factors need to be studied. 
- High Phase (Six phase) order systems have several advantages such as lower voltage requirement to transfer higher amount of power when compared with three phase system. The line voltage determines the clearances distance and hence more line compaction is possible in high phase system. However, future research has to be conducted in line protection as 24 different faults are possible for six phase system. This could be solved with the development of various numerical relays.

- Application of the aforementioned techniques on a larger system and understanding the effects on electric grid need to be studied.

- Transmission planning includes building new transmission line and upgrading voltage of the line. However application of the discussed techniques could reduce the number of lines required. 


\section{REFERENCES}

[1] U.S.-Canada Power System Outage Task Force, "Final report on the august 14, 2003 blackout in the United States and Canada: causes and recommendations,” April 2004, p. 5, https://reports.energy.gov/BlackoutFinal-Web.pdf.

[2] Barrie Badenhorst, Chris van der Merwe, Jacques de Vos, "China unveils 1000 kV AC transmission grid,” Energize , July 2009, http://eepublishers.co.za/article/energize-july-2009.html

[3] Transmission and distribution world, "Vijai Electricals Hands Over 1200-kV Power Transformer to Power Grid Corporation of India Ltd,” August 2011.

[4] Stan Mark Kaplan, Congressional Research Service, "Electric power transmission: background and policy issues,” April 2009, http://fpc.state.gov/documents/organization/122949.pdf

[5] Renewable portfolio standards fact sheet, http://www.epa.gov/chp/statepolicy/renewable fs.html

[6] National Renewable Energy Laboratory, "Renewable portfolio standards in the states: balancing goals and implementation strategies," December 2007

[7] Electric Power Research Institute, "Transmission line reference book $345 \mathrm{kV}$ and above," Second edition: The "red book", 1982

[8] Electric Power Research Institute, "AC transmission line reference book- 200 kV and above," Third edition: The "red book”, 2005

[9] Exxon Mobil report, "2012 The outlook of energy: A view to 2040," http://www.exxonmobil.com/Corporate/files/news_pub_eo.pdf

[10] United States Department of Energy-Office of Electric Transmission and Distribution, "GRID 2030 - a national vision for electricity's second 100 years," July 2003.

http://energy.gov/oe/downloads/grid-2030-national-vision-electricity-ssecond-100-years

[11] U. S. Department of Agriculture, "Engineering and environmental staff rural utilities service,” December 1998. 
[12] M. Shahidehpour, "Investing in expansion: the many issues that cloud transmission planning,” IEEE Power and Energy Magazine, vol.2, no.1, pp. 14- 18, January-February 2004.

[13] United State Department of Energy, "National electric transmission congestion study,” December 2009.

[14] Western Electric Coordinating Council, "2009 western interconnection transmission path utilization study,” June 2010.

[15] Western Electric Coordinating Council, "10 - Year regional transmission plan, 2020 study report,” September 2011.

[16] Electric Reliability Council of Texas, "Report of existing and potential electric system constrains and needs,” December 2011.

[17] Edison Electric Institute, "Transforming America's power industry: The investment challenge 2010-2030,” November 2008.

[18] IEEE National Electrical Safety Code (NESC) C2 - 2007.

[19] J. D. Glover, M. S. Sarma, T. J. Overbye, "Power system analysis and design”, Fourth edition, 2008.

[20] A.A. Fouad, P. M. Anderson, "Power system control and stability," Second Edition, 2003.

[21] R. Gutman, P. P. Marchenko, R. D. Dunlop, "Analytical development of loadability characteristics for EHV and UHV transmission lines," IEEE Transactions on Power Apparatus and Systems, vol.98, no.2, pp.606-617, March 1979.

[22] P. Kundur, J.Paserba, V. Ajjarapu, G.Andersson, A. Bose, C.Canizares, N. Hatziargyriou, D. Hill, A.Stankovic, C. Taylor, T. Van Cutsem, V.Vittal, "Definition and classification of power system stability IEEE/CIGRE joint task force on stability terms and definitions," IEEE Transactions on Power Systems, vol.19, no.3, pp. 1387- 1401, August 2004.

[23] Scientific Committee on Emerging and Newly Indentified Health Risks (SCENIHR), "Possible effects of electromagnetic fields (EMF) on human health,” March 2007. 
[24] K. Wasti, "Monitoring of ongoing research on the health effects of high voltage transmission lines,” Virginia Department of Health, March 1997.

[25] World Health Organization, "Framework for developing health-based EMF standards,” 2006.

[26] IEEE C95.6, "IEEE standard for safety levels with respect to human exposure to electromagnetic fields, $0-3 \mathrm{kHz}$, October 2002

[27] Y. Matsumoto, O. Sakuma, K. Shinjo, M. Saiki, T. Wakai, T. Sakai, H. Nagasaka, H. Motoyama, M. Ishii, "Measurement of lightning surges on test transmission line equipped with arresters struck by natural and triggered lightning,” IEEE Transactions on Power Delivery, vol. 11, no. 2, pp.996-1002, April 1996

[28] H. C. Barnes, L. O. Barthold, "High Phase Order Power Transmission," presented by CIGRE SC 31, ELECTRA, no. 24, pp. 139-153, 1973.

[29] J. R. Stewart, L. J. Oppel, G.C Thomann, T. F. Dorazio, M. T. Brown, “Insulation coordination, environmental and system analysis of existing double circuit line reconfigured to six-phase operation,” IEEE Power Engineering Society, Transmission and Distribution Conference, 1991, pp. 978-982, 22-27 September 1991.

[30] J. R. Stewart, T. L. Hudson, “138 kV 12-phase as an alternative to 345 kV 3phase,” IEEE Conference Proceedings Southeastcon '88, pp. 258-263, 11-13 April 1988.

[31] Transmission line http://www.cpuc.ca.gov/environment/info/esa/sjxvl/deir/c2_proj description.p $\underline{\mathrm{df}}$

[32] Alcan cable bare overhead transmission and distribution conductors: http://www.cable.alcan.com/NR/rdonlyres/1EB04891-D36E-45D0-9E2D 9B6F45147FE3/0/BareCableBrochure.pdf

[33] S. A. Jumaat, M. W. Mustafa, "Analysis of six phase system for transmission line," International Power Engineering and Optimization Conference (PEOCO), Malaysia, June 2008.

[34] PowerWorld sample case http://www.powerworld.com/educator.asp

[35] IEEE 118 bus test system 
motor.ece.iit.edu/data/JEAS IEEE118.doc

[36] ICNIRP Guidelines, "For limiting exposure to time-varying electric, magnetic and electromagnetic fields (up to $300 \mathrm{GHz}$ ), 1998. 
APPENDIX A

STANDARDS FOR ELECTRIC AND MAGNETIC FIELD 
Table A-1Electric and magnetic field standards established by various states in the United States [8]

\begin{tabular}{|c|c|c|}
\hline $\begin{array}{c}\text { Various States in the } \\
\text { United States }\end{array}$ & $\begin{array}{c}\text { Electric field at the edge } \\
\text { of right of way }(\mathrm{kV} / \mathrm{m})\end{array}$ & $\begin{array}{c}\text { Magnetic field at the edge } \\
\text { of right of way }(\mathrm{mG} / \mathrm{m})\end{array}$ \\
\hline New York & 1.6 & 200 \\
\hline Florida & 3 & 150 \\
\hline Montana & 1 & -- \\
\hline New Jersey & 3 & -- \\
\hline
\end{tabular}

Table A-2Occupational and public exposure by ICNIRP [36]

\begin{tabular}{|c|c|c|}
\hline Exposure & Electric field $(\mathrm{kV} / \mathrm{m})$ & Magnetic field $(\mathrm{G} / \mathrm{m})$ \\
\hline Occupational exposure & 8.4 & 4.167 \\
\hline Public exposure & 4.167 & 0.833 \\
\hline
\end{tabular}


APPENDIX B

PARAMETERS FOR IEEE 9 BUS SYSTEM 
Table B-1Generator parameters for IEEE 9 bus test system

\begin{tabular}{|c|c|}
\hline Generator parameters & $\begin{array}{c}\text { Per unit (P.U.) on 100 } \\
\text { MVA base }\end{array}$ \\
\hline$H$ (Inertia) & 6.4 \\
\hline$D$ (Damping) & 0 \\
\hline$R_{a}$ & 0.8958 \\
\hline$X_{d}$ & 0.8645 \\
\hline$X_{q}$ & 0.1198 \\
\hline$X^{\prime}{ }_{d}$ & 0.1198 \\
\hline$X^{\prime \prime}{ }_{d}=X^{\prime}{ }^{\prime}{ }_{q}$ & 0.0599 \\
\hline$X_{l}$ & 6.0 \\
\hline$T^{\prime}{ }_{d 0}$ & 0.5350 \\
\hline$T^{\prime \prime}{ }_{d 0}=T^{\prime}{ }{ }_{q 0}$ & \\
\hline
\end{tabular}


APPENDIX C

DATA FOR 118 BUS TEST SYSTEM 
Table C-1 Bus data

\begin{tabular}{|c|c|c|c|c|c|c|c|c|c|c|}
\hline No & $\begin{array}{c}\text { No- } \\
\text { minal } \\
\mathrm{kV}\end{array}$ & PU & $\begin{array}{l}\text { Volt } \\
(\mathrm{kV})\end{array}$ & $\begin{array}{l}\text { Angle } \\
\text { (Deg) }\end{array}$ & $\begin{array}{l}\text { Load } \\
\text { MW }\end{array}$ & $\begin{array}{l}\text { Load } \\
\text { MVar }\end{array}$ & $\begin{array}{l}\text { Gen } \\
\text { MW }\end{array}$ & $\begin{array}{l}\text { Gen } \\
\text { MVar }\end{array}$ & $\begin{array}{c}\text { Switched } \\
\text { Shunts } \\
\text { MVar }\end{array}$ & Zone \\
\hline 1 & 1.00 & 0.95 & 0.957 & -18.2 & 51.00 & 27.00 & & & & 1 \\
\hline 2 & 1.00 & 0.97 & 0.972 & -17.7 & 20.00 & 9.00 & & & & 1 \\
\hline 3 & 1.00 & 0.96 & 0.969 & $\begin{array}{l}-17.3 \\
\end{array}$ & 39.00 & 10.00 & & & & 1 \\
\hline 4 & 1.00 & 0.99 & 0.998 & -13.6 & 30.00 & 12.00 & -9 & $\begin{array}{l}-15.5 \\
\end{array}$ & & 1 \\
\hline 5 & 1.00 & 1.00 & 1.002 & -13.2 & & & & & -40.17 & 1 \\
\hline 6 & 1.00 & 0.99 & 0.99 & -15.9 & 52.00 & 22.00 & 0 & 15.8 & & 1 \\
\hline 7 & 1.00 & 0.98 & 0.989 & -16.3 & 19.00 & 2.00 & & & & 1 \\
\hline 8 & 1.00 & 1.01 & 1.015 & -8.13 & & & -28 & $\begin{array}{l}61.6 \\
\end{array}$ & & 1 \\
\hline 9 & 1.00 & 1.04 & 1.043 & -0.87 & & & & & & 1 \\
\hline 10 & 1.00 & 1.05 & 1.05 & 6.71 & & & 450 & -50.9 & & 1 \\
\hline 11 & 1.00 & 0.98 & 0.985 & -16.2 & 70.00 & 23.00 & & & & 1 \\
\hline 12 & 1.00 & 0.99 & 0.99 & -16.7 & 47.00 & 10.00 & 85 & 88.3 & & 1 \\
\hline 13 & 1.00 & 0.96 & 0.968 & -17.5 & 34.00 & 16.00 & & & & 1 \\
\hline 14 & 1.00 & 0.98 & 0.984 & -17.4 & 14.00 & 1.00 & & & & 1 \\
\hline 15 & 1.00 & 0.97 & 0.97 & -17.7 & 90.00 & 30.00 & 0 & 2.71 & & 1 \\
\hline 16 & 1.00 & 0.98 & 0.984 & -17 & 25.00 & 10.00 & & & & 1 \\
\hline 17 & 1.00 & 0.99 & 0.995 & -15.2 & 11.00 & 3.00 & & & 0 & 1 \\
\hline 18 & 1.00 & 0.97 & 0.973 & -17.4 & 60.00 & 34.00 & 0 & 25.3 & & 1 \\
\hline 19 & 1.00 & 0.96 & 0.963 & -17.8 & 45.00 & 25.00 & 0 & -8 & & 1 \\
\hline 20 & 1.00 & 0.95 & 0.958 & -17 & 18.00 & 3.00 & & & & 1 \\
\hline 21 & 1.00 & 0.95 & 0.959 & -15.4 & 14.00 & 8.00 & & & & 1 \\
\hline 22 & 1.00 & 0.96 & 0.97 & -12.9 & 10.00 & 5.00 & & & & 1 \\
\hline 23 & 1.00 & 0.99 & 1 & -7.99 & 7.00 & 3.00 & & & & 1 \\
\hline 24 & 1.00 & 0.99 & 0.992 & -8.23 & & & -13 & $\begin{array}{l}-13.9 \\
\end{array}$ & & 1 \\
\hline 25 & 1.00 & 1.05 & 1.05 & -1 & & & 220 & 49.6 & & 1 \\
\hline 26 & 1.00 & 1.01 & 1.015 & 0.78 & & & 314 & 9.49 & & 1 \\
\hline 27 & 1.00 & 0.96 & 0.968 & -13.5 & 62.00 & 13.00 & -9 & 2.34 & & 1 \\
\hline 28 & 1.00 & 0.96 & 0.962 & -15.1 & 17.00 & 7.00 & & & & 1 \\
\hline 29 & 1.00 & 0.96 & 0.963 & -16 & 24.00 & 4.00 & & & & 1 \\
\hline 30 & 1.00 & 0.98 & 0.986 & -10.2 & & & & & & 1 \\
\hline 31 & 1.00 & 0.96 & 0.967 & -15.8 & 43.00 & 27.00 & 7 & 3.96 & & 1 \\
\hline 32 & 1.00 & 0.96 & 0.964 & -14 & 59.00 & 23.00 & 0 & -14 & & 1 \\
\hline 33 & 1.00 & 0.97 & 0.972 & $\begin{array}{l}-18.1 \\
\end{array}$ & 23.00 & 9.00 & & & & 1 \\
\hline 34 & 1.00 & 0.98 & 0.986 & -17.3 & 59.00 & 26.00 & 0 & -8 & 13.61 & 1 \\
\hline
\end{tabular}




\begin{tabular}{|c|c|c|c|c|c|c|c|c|c|c|}
\hline No & $\begin{array}{c}\text { No- } \\
\text { minal } \\
\mathrm{kV}\end{array}$ & PU & $\begin{array}{c}\text { Volt } \\
(\mathrm{kV})\end{array}$ & $\begin{array}{l}\text { Angle } \\
\text { (Deg) }\end{array}$ & $\begin{array}{l}\text { Load } \\
\text { MW }\end{array}$ & $\begin{array}{l}\text { Load } \\
\text { MVar }\end{array}$ & $\begin{array}{l}\text { Gen } \\
\text { MW }\end{array}$ & $\begin{array}{c}\text { Gen } \\
\text { MVar }\end{array}$ & $\begin{array}{l}\text { Switched } \\
\text { Shunts } \\
\text { MVar }\end{array}$ & Zone \\
\hline 35 & 1.00 & 0.98 & 0.981 & -17.8 & 33.00 & 9.00 & & & & 1 \\
\hline 36 & 1.00 & 0.98 & 0.98 & -17.8 & 31.00 & 17.00 & 0 & -1.73 & & 1 \\
\hline 37 & 1.00 & 0.99 & 0.992 & -16.9 & & & & & -24.61 & 1 \\
\hline 38 & 1.00 & 0.96 & 0.963 & -12.1 & & & & & & 1 \\
\hline 39 & 1.00 & 0.97 & 0.971 & -19.5 & 27.00 & 11.00 & & & & 1 \\
\hline 40 & 1.00 & 0.97 & 0.97 & -20.1 & 20.00 & 23.00 & -46 & 25.3 & & 1 \\
\hline 41 & 1.00 & 0.96 & 0.967 & -20.2 & 37.00 & 10.00 & & & & 1 \\
\hline 42 & 1.00 & 0.98 & 0.985 & -17.7 & 37.00 & 23.00 & -59 & 21.9 & & 1 \\
\hline 43 & 1.00 & 0.97 & 0.979 & -17.5 & 18.00 & 7.00 & & & & 1 \\
\hline 44 & 1.00 & 0.98 & 0.985 & -15.2 & 16.00 & 8.00 & & & 9.71 & 1 \\
\hline 45 & 1.00 & 0.98 & 0.987 & -13.5 & 53.00 & 22.00 & & & 9.74 & 1 \\
\hline 46 & 1.00 & 1.00 & 1.005 & -10.7 & 28.00 & 10.00 & 19 & -5.68 & 10.1 & 1 \\
\hline 47 & 1.00 & 1.01 & 1.017 & -8.58 & 34.00 & 0.00 & & & & 1 \\
\hline 48 & 1.00 & 1.02 & 1.021 & -9.27 & 20.00 & 11.00 & & & 15.63 & 1 \\
\hline 49 & 1.00 & 1.02 & 1.025 & -8.26 & 87.00 & 30.00 & 204 & 108 & & 1 \\
\hline 50 & 1.00 & 1.00 & 1.001 & -10.1 & 17.00 & 4.00 & & & & 1 \\
\hline 51 & 1.00 & 0.96 & 0.968 & -12.5 & 17.00 & 8.00 & & & & 1 \\
\hline 52 & 1.00 & 0.95 & 0.958 & -13.4 & 18.00 & 5.00 & & & & 1 \\
\hline 53 & 1.00 & 0.94 & 0.946 & -14.2 & 23.00 & 11.00 & & & & 1 \\
\hline 54 & 1.00 & 0.95 & 0.955 & -13.1 & 113.0 & 32.00 & 48 & -29 & & 1 \\
\hline 55 & 1.00 & 0.95 & 0.952 & -13.5 & 63.00 & 22.00 & 0 & 1.11 & & 1 \\
\hline 56 & 1.00 & 0.95 & 0.955 & -13.3 & 84.00 & 18.00 & 0 & -8 & & 1 \\
\hline 57 & 1.00 & 0.97 & 0.971 & -12.3 & 12.00 & 3.00 & & & & 1 \\
\hline 58 & 1.00 & 0.95 & 0.96 & -13.1 & 12.00 & 3.00 & & & & 1 \\
\hline 59 & 1.00 & 0.98 & 0.985 & -10.4 & 277.0 & 113.00 & 155 & 83.3 & & 1 \\
\hline 60 & 1.00 & 0.99 & 0.993 & -6.95 & 78.00 & 3.00 & & & & 1 \\
\hline 61 & 1.00 & 0.99 & 0.995 & -6.06 & & & 160 & -41.6 & & 1 \\
\hline 62 & 1.00 & 0.99 & 0.998 & -6.79 & 77.00 & 14.00 & 0 & 0.6 & & 1 \\
\hline 63 & 1.00 & 0.96 & 0.969 & -7.22 & & & & & & 1 \\
\hline 64 & 1.00 & 0.98 & 0.984 & -5.56 & & & & & & 1 \\
\hline 65 & 1.00 & 1.00 & 1.005 & -2.55 & & & 391 & 78.8 & & 1 \\
\hline 66 & 1.00 & 1.05 & 1.05 & -3.3 & 39.00 & 18.00 & 392 & 16.8 & & 1 \\
\hline 67 & 1.00 & 1.01 & 1.02 & -5.69 & 28.00 & 7.00 & & & & 1 \\
\hline 68 & 1.00 & 1.00 & 1.003 & -2.62 & & & & & & 1 \\
\hline 70 & 1.00 & 0.98 & 0.984 & -7.11 & 66.00 & 20.00 & 0 & 6.6 & & 1 \\
\hline 71 & 1.00 & 0.98 & 0.987 & -7.49 & & & & & & 1 \\
\hline 72 & 1.00 & 0.98 & 0.98 & -8.42 & & & -12 & -11.2 & & 1 \\
\hline
\end{tabular}




\begin{tabular}{|c|c|c|c|c|c|c|c|c|c|c|}
\hline No & $\begin{array}{c}\text { No- } \\
\text { minal } \\
\mathrm{kV} \\
\end{array}$ & PU & $\begin{array}{c}\text { Volt } \\
(\mathrm{kV})\end{array}$ & $\begin{array}{l}\text { Angle } \\
\text { (Deg) }\end{array}$ & $\begin{array}{l}\text { Load } \\
\text { MW }\end{array}$ & $\begin{array}{l}\text { Load } \\
\text { MVar }\end{array}$ & $\begin{array}{l}\text { Gen } \\
\text { MW }\end{array}$ & $\begin{array}{c}\text { Gen } \\
\text { MVar }\end{array}$ & $\begin{array}{c}\text { Switched } \\
\text { Shunts } \\
\text { MVar }\end{array}$ & Zone \\
\hline 73 & 1.00 & 0.99 & 0.991 & -7.7 & & & -6 & 9.63 & & 1 \\
\hline 74 & 1.00 & 0.95 & 0.959 & -8.08 & 68.00 & 27.00 & 0 & -6 & 11.03 & 1 \\
\hline 75 & 1.00 & 0.96 & 0.968 & -6.83 & 47.00 & 11.00 & & & & 1 \\
\hline 76 & 1.00 & 0.94 & 0.943 & -7.86 & 68.00 & 36.00 & 0 & 0.78 & & 1 \\
\hline 77 & 1.00 & 1.01 & 1.012 & -2.91 & 61.00 & 28.00 & 0 & -20 & & 1 \\
\hline 78 & 1.00 & 1.00 & 1.008 & -3.3 & 71.00 & 26.00 & & & & 1 \\
\hline 79 & 1.00 & 1.01 & 1.013 & -3.16 & 39.00 & 32.00 & & & 20.53 & 1 \\
\hline 80 & 1.00 & 1.04 & 1.04 & -1.38 & 130.0 & 26.00 & 477 & 126 & & 1 \\
\hline 81 & 1.00 & 0.99 & 0.997 & -2.13 & & & & & & 1 \\
\hline 82 & 1.00 & 1 & 1 & -3 & 54.00 & 27.00 & 0 & 21.9 & 20 & 1 \\
\hline 83 & 1.00 & 0.99 & 0.994 & -2.07 & 20.00 & 10.00 & & & 9.88 & 1 \\
\hline 84 & 1.00 & 0.98 & 0.985 & 0.07 & 11.00 & 7.00 & & & & 1 \\
\hline 85 & 1.00 & 0.98 & 0.988 & 1.44 & 24.00 & 15.00 & 0 & -8 & & 1 \\
\hline 86 & 1.00 & 0.98 & 0.989 & 0.1 & 21.00 & 10.00 & & & & 1 \\
\hline 87 & 1.00 & 1.01 & 1.015 & 0.37 & & & 4 & 9.95 & & 1 \\
\hline 88 & 1.00 & 0.98 & 0.989 & 4.2 & 48.00 & 10.00 & & & & 1 \\
\hline 89 & 1.00 & 1.00 & 1.005 & 8 & & & 607 & -19.8 & & 1 \\
\hline 90 & 1.00 & 0.98 & 0.985 & 3.46 & 78.00 & 42.00 & -85 & 44.4 & & 1 \\
\hline 91 & 1.00 & 0.98 & 0.98 & 3.7 & & & -10 & -19.1 & & 1 \\
\hline 92 & 1.00 & 0.99 & 0.998 & 4.43 & 65.00 & 10.00 & 0 & -3 & & 1 \\
\hline 93 & 1.00 & 0.99 & 0.991 & 1.21 & 12.00 & 7.00 & & & & 1 \\
\hline 94 & 1.00 & 0.99 & 0.994 & -1.14 & 30.00 & 16.00 & & & & 1 \\
\hline 95 & 1.00 & 0.98 & 0.985 & -2.23 & 42.00 & 31.00 & & & & 1 \\
\hline 96 & 1.00 & 0.99 & 0.998 & -2.55 & 38.00 & 15.00 & & & & 1 \\
\hline 97 & 1.00 & 1.01 & 1.014 & -2.32 & 15.00 & 9.00 & & & & 1 \\
\hline 98 & 1.00 & 1.02 & 1.024 & -2.72 & 34.00 & 8.00 & & & & 1 \\
\hline 99 & 1.00 & 1.01 & 1.01 & -2.89 & & & -42 & -17.6 & & 1 \\
\hline 100 & 1.00 & 1.01 & 1.017 & -1.73 & 37.00 & 18.00 & 252 & 75.4 & & 1 \\
\hline 101 & 1.00 & 0.99 & 0.995 & 0.02 & 22.00 & 15.00 & & & & 1 \\
\hline 102 & 1.00 & 0.99 & 0.995 & 2.86 & 5.00 & 3.00 & & & & 1 \\
\hline 103 & 1.00 & 1.00 & 1.006 & -5.37 & 23.00 & 16.00 & 40 & 40 & & 1 \\
\hline 104 & 1.00 & 0.98 & 0.988 & -8.26 & 38.00 & 25.00 & 0 & 23 & & 1 \\
\hline 105 & 1.00 & 0.98 & 0.982 & -9.35 & 31.00 & 26.00 & 0 & 23 & 19.3 & 1 \\
\hline 106 & 1.00 & 0.97 & 0.973 & -9.5 & 43.00 & 16.00 & & & & 1 \\
\hline 107 & 1.00 & 0.95 & 0.952 & -12.1 & 28.00 & 12.00 & -22 & -8.71 & 5.44 & 1 \\
\hline 108 & 1.00 & 0.97 & 0.977 & -10.4 & 2.00 & 1.00 & & & & 1 \\
\hline 109 & 1.00 & 0.97 & 0.975 & -10.8 & 8.00 & 3.00 & & & & 1 \\
\hline
\end{tabular}




\begin{tabular}{|c|c|c|c|c|c|c|c|c|c|c|}
\hline No & $\begin{array}{c}\text { No- } \\
\text { minal } \\
\mathrm{kV}\end{array}$ & PU & $\begin{array}{c}\text { Volt } \\
(\mathrm{kV})\end{array}$ & $\begin{array}{c}\text { Angle } \\
(\mathrm{Deg})\end{array}$ & $\begin{array}{c}\text { Load } \\
\text { MW }\end{array}$ & $\begin{array}{c}\text { Load } \\
\text { MVar }\end{array}$ & $\begin{array}{c}\text { Gen } \\
\text { MW }\end{array}$ & $\begin{array}{c}\text { Gen } \\
\text { MVar }\end{array}$ & $\begin{array}{c}\text { Switched } \\
\text { Shunts } \\
\text { MVar }\end{array}$ & Zone \\
\hline 110 & 1.00 & 0.97 & 0.973 & -11.5 & 39.00 & 30.00 & 0 & -7.48 & 5.68 & 1 \\
\hline 111 & 1.00 & 0.98 & 0.98 & -9.87 & & & 36 & -1.84 & & 1 \\
\hline 112 & 1.00 & 0.97 & 0.975 & -14.6 & 25.00 & 13.00 & -43 & 41.5 & & 1 \\
\hline 113 & 1.00 & 0.99 & 0.993 & -15.3 & & & -6 & 34.4 & & 1 \\
\hline 114 & 1.00 & 0.96 & 0.96 & -14.3 & 8.00 & 3.00 & & & & 1 \\
\hline 115 & 1.00 & 0.96 & 0.96 & -14.3 & 22.00 & 7.00 & & & & 1 \\
\hline 116 & 1.00 & 1.00 & 1.005 & -3.06 & & & -184 & 50.3 & & 1 \\
\hline 117 & 1.00 & 0.98 & 0.982 & -16.7 & 20.00 & 8.00 & & & & 1 \\
\hline 118 & 1.00 & 0.94 & 0.95 & -7.77 & 33.00 & 15.00 & & & & 1 \\
\hline
\end{tabular}

Table C-2 Transmission line data

\begin{tabular}{|c|c|c|c|c|c|c|c|c|c|}
\hline $\begin{array}{c}\text { From } \\
\text { No. }\end{array}$ & $\begin{array}{c}\text { To } \\
\text { No. }\end{array}$ & $\begin{array}{c}\text { Cir- } \\
\text { cuit }\end{array}$ & $\begin{array}{c}\text { Branc } \\
\mathrm{h}\end{array}$ & $\begin{array}{c}\text { MW } \\
\text { From }\end{array}$ & $\begin{array}{c}\text { MVar } \\
\text { From }\end{array}$ & $\begin{array}{c}\text { MVA } \\
\text { From }\end{array}$ & $\begin{array}{c}\text { Line } \\
\text { MVA }\end{array}$ & $\begin{array}{c}\text { of MVA } \\
\text { Limit } \\
\text { (Max) }\end{array}$ & $\begin{array}{c}\text { MW } \\
\text { Loss }\end{array}$ \\
\hline 12 & 117 & 1 & Line & 20.1 & 4.6 & 20.7 & 100 & 21.5 & 0.15 \\
\hline 11 & 12 & 1 & Line & 34.2 & -35 & 48.9 & 100 & 48.9 & 0.14 \\
\hline 8 & 30 & 1 & Line & 74.5 & 27.1 & 79.3 & 100 & 105.1 & 0.35 \\
\hline 24 & 70 & 1 & Line & -3.9 & -2.1 & 4.4 & 100 & 8.7 & 0.02 \\
\hline 6 & 7 & 1 & Line & 35.4 & -4.7 & 35.8 & 100 & 35.8 & 0.06 \\
\hline 27 & 28 & 1 & Line & 31.2 & -0.3 & 31.2 & 100 & 31.2 & 0.2 \\
\hline 19 & 34 & 1 & Line & -5.4 & -10.1 & 11.4 & 100 & 11.4 & 0.06 \\
\hline 17 & 31 & 1 & Line & 11.3 & 12.6 & 16.9 & 100 & 19.4 & 0.16 \\
\hline 30 & 38 & 1 & Line & 62.8 & 16.3 & 64.9 & 0 & 0 & 0.25 \\
\hline 23 & 32 & 1 & Line & 90.7 & 5.1 & 90.9 & 100 & 90.9 & 2.65 \\
\hline 25 & 27 & 1 & Line & 142.2 & 30 & 145.3 & 500 & 29.1 & 6.28 \\
\hline 15 & 19 & 1 & Line & 11 & 12.4 & 16.6 & 100 & 17.2 & 0.04 \\
\hline & & & & & & & & & \\
\hline 1 & 2 & 1 & Line & -12.3 & -11.8 & 17.1 & 100 & 17.1 & 0.09 \\
\hline 23 & 24 & 1 & Line & 12.1 & 10 & 15.6 & 100 & 19 & 0.04 \\
\hline 22 & 23 & 1 & Line & -52.9 & -6.6 & 53.3 & 100 & 54.4 & 1.03 \\
\hline 23 & 25 & 1 & Line & -163 & -25.4 & 165.7 & 500 & 34.5 & 4.25 \\
\hline 70 & 75 & 1 & Line & 0 & 9.3 & 9.3 & 100 & 12.5 & 0.05 \\
\hline 17 & 113 & 1 & Line & 8.8 & 4.4 & 9.8 & 100 & 10.1 & 0.01 \\
\hline 32 & 113 & 1 & Line & 6 & -18 & 19 & 100 & 19 & 0.18 \\
\hline 15 & 33 & 1 & Line & 5.4 & -4.4 & 7 & 100 & 7 & 0.02 \\
\hline
\end{tabular}




\begin{tabular}{|c|c|c|c|c|c|c|c|c|c|}
\hline $\begin{array}{c}\text { From } \\
\text { No. }\end{array}$ & $\begin{array}{l}\text { To } \\
\text { No. }\end{array}$ & $\begin{array}{l}\text { Cir- } \\
\text { cuit }\end{array}$ & $\begin{array}{l}\text { Branc } \\
\text { h Type }\end{array}$ & $\begin{array}{l}\text { MW } \\
\text { From }\end{array}$ & $\begin{array}{l}\text { MVar } \\
\text { From }\end{array}$ & $\begin{array}{l}\text { MVA } \\
\text { From }\end{array}$ & $\begin{array}{l}\text { Line } \\
\text { MVA }\end{array}$ & $\begin{array}{c}\text { \% of MVA } \\
\text { Limit } \\
\text { (Max) }\end{array}$ & $\begin{array}{l}\text { MW } \\
\text { Loss }\end{array}$ \\
\hline 29 & 31 & 1 & Line & -10 & -8.2 & 12.9 & 100 & 12.9 & 0.02 \\
\hline 4 & 5 & 1 & Line & -103 & -27.3 & 106.7 & 500 & 21.4 & 0.21 \\
\hline 14 & 15 & 1 & Line & 4 & 3.2 & 5.1 & 100 & 8.9 & 0.03 \\
\hline 3 & 12 & 1 & Line & -9.8 & -11.6 & 15.2 & 100 & 15.2 & 0.1 \\
\hline 16 & 17 & 1 & Line & -17.4 & -3.8 & 17.8 & 100 & 17.8 & 0.14 \\
\hline 26 & 30 & 1 & Line & 223.8 & -12.1 & 224.2 & 500 & 44.8 & 3.98 \\
\hline 27 & 32 & 1 & Line & 12.8 & 0.8 & 12.8 & 100 & 13 & 0.04 \\
\hline 71 & 73 & 1 & Line & 6 & -10.7 & 12.3 & 100 & 12.3 & 0.01 \\
\hline 20 & 21 & 1 & Line & -28.3 & 4.8 & 28.7 & 100 & 29.1 & 0.17 \\
\hline 114 & 115 & 1 & Line & 1.2 & 0.7 & 1.4 & 100 & 1.5 & 0 \\
\hline 5 & 6 & 1 & Line & 88.4 & 4.3 & 88.5 & 100 & 88.5 & 0.93 \\
\hline 8 & 5 & 1 & $\begin{array}{l}\text { Trans- } \\
\text { former }\end{array}$ & 338.2 & 124.4 & 360.3 & 0 & 0 & 0 \\
\hline 12 & 14 & 1 & Line & 18.1 & 2.7 & 18.3 & 100 & 18.5 & 0.07 \\
\hline 1 & 3 & 1 & Line & -38.7 & -15.2 & 41.6 & 100 & 41.7 & 0.24 \\
\hline 74 & 75 & 1 & Line & -51.9 & -7 & 52.3 & 100 & 52.7 & 0.37 \\
\hline 71 & 72 & 1 & Line & 9.1 & -0.6 & 9.1 & 100 & 9.7 & 0.04 \\
\hline 70 & 71 & 1 & Line & 15.2 & -12 & 19.4 & 100 & 19.4 & 0.03 \\
\hline 9 & 10 & 1 & Line & -445 & -24.6 & 445.9 & 500 & 90.6 & 4.78 \\
\hline 30 & 17 & 1 & $\begin{array}{l}\text { Trans- } \\
\text { former }\end{array}$ & 231.2 & 94.1 & 249.6 & 0 & 0 & 0 \\
\hline 32 & 114 & 1 & Line & 9.2 & 2.3 & 9.5 & 100 & 9.9 & 0.01 \\
\hline 113 & 31 & 1 & Line & 8.6 & 25.9 & 27.2 & 1000 & 2.7 & 0 \\
\hline 31 & 32 & 1 & Line & -26.4 & 10.5 & 28.4 & 100 & 29.2 & 0.27 \\
\hline 12 & 16 & 1 & Line & 7.6 & 4.2 & 8.7 & 100 & 9.8 & 0.02 \\
\hline 5 & 11 & 1 & Line & 77.1 & 3.1 & 77.2 & 100 & 77.2 & 1.21 \\
\hline 27 & 115 & 1 & Line & 20.9 & 4.6 & 21.4 & 100 & 21.7 & 0.08 \\
\hline 7 & 12 & 1 & Line & 16.4 & -6.5 & 17.6 & 100 & 17.6 & 0.03 \\
\hline 2 & 12 & 1 & Line & -32.4 & -18.7 & 37.4 & 100 & 37.4 & 0.27 \\
\hline 3 & 5 & 1 & Line & -68.1 & -13.4 & 69.4 & 100 & 71.2 & 1.23 \\
\hline 24 & 72 & 1 & Line & 2.9 & 2.9 & 4.2 & 100 & 8.2 & 0.02 \\
\hline 28 & 29 & 1 & Line & 14 & -6.2 & 15.3 & 100 & 15.3 & 0.06 \\
\hline 8 & 9 & 1 & Line & -440 & -89.8 & 449.7 & 500 & 89.9 & 4.54 \\
\hline 26 & 25 & 1 & $\begin{array}{l}\text { Trans- } \\
\text { former }\end{array}$ & 90.2 & 21.6 & 92.7 & 0 & 0 & 0 \\
\hline 13 & 15 & 1 & Line & 0.6 & -3.8 & 3.9 & 100 & 3.9 & 0 \\
\hline
\end{tabular}




\begin{tabular}{|c|c|c|c|c|c|c|c|c|c|}
\hline $\begin{array}{c}\text { From } \\
\text { No. }\end{array}$ & $\begin{array}{l}\text { To } \\
\text { No. }\end{array}$ & $\begin{array}{l}\text { Cir- } \\
\text { cuit }\end{array}$ & $\begin{array}{c}\text { Branc } \\
\text { h }\end{array}$ & $\begin{array}{l}\text { MW } \\
\text { From }\end{array}$ & $\begin{array}{l}\text { MVar } \\
\text { From }\end{array}$ & $\begin{array}{l}\text { MVA } \\
\text { From }\end{array}$ & $\begin{array}{l}\text { Line } \\
\text { MVA }\end{array}$ & $\begin{array}{c}\% \text { of MVA } \\
\text { Limit } \\
\text { (Max) }\end{array}$ & $\begin{array}{l}\text { MW } \\
\text { Loss }\end{array}$ \\
\hline 17 & 18 & 1 & Line & 79.2 & 25.3 & 83.2 & 100 & 83.2 & 0.86 \\
\hline 4 & 11 & 1 & Line & 64.1 & -0.2 & 64.1 & 100 & 64.1 & 0.86 \\
\hline 18 & 19 & 1 & Line & 18.4 & 14.2 & 23.3 & 100 & 23.7 & 0.07 \\
\hline 70 & 74 & 1 & Line & 16.3 & 12.4 & 20.5 & 100 & 22 & 0.19 \\
\hline 15 & 17 & 1 & Line & -101 & -25.3 & 105 & 500 & 21.3 & 1.53 \\
\hline 75 & 77 & 1 & Line & -36.2 & -11.4 & 37.9 & 100 & 38.2 & 0.89 \\
\hline 75 & 118 & 1 & Line & 39 & 24.8 & 46.2 & 100 & 46.2 & 0.33 \\
\hline 11 & 13 & 1 & Line & 34.9 & 11.4 & 36.7 & 100 & 36.7 & 0.32 \\
\hline 21 & 22 & 1 & Line & -42.5 & -2 & 42.5 & 100 & 42.9 & 0.41 \\
\hline 19 & 20 & 1 & Line & -10.3 & 5.3 & 11.6 & 100 & 13 & 0.04 \\
\hline 37 & 40 & 1 & Line & 33.2 & 0.2 & 33.2 & 100 & 33.2 & 0.67 \\
\hline 69 & 77 & 1 & Line & 55.3 & 2.7 & 55.4 & 100 & 55.4 & 0.9 \\
\hline 37 & 39 & 1 & Line & 43.7 & 6.3 & 44.2 & 100 & 44.2 & 0.64 \\
\hline 38 & 37 & 1 & $\begin{array}{l}\text { Trans- } \\
\text { former }\end{array}$ & 226.4 & 114.2 & 253.5 & 0 & 0 & 0 \\
\hline 68 & 116 & 1 & Line & 184.1 & -65.4 & 195.4 & 500 & 39.1 & 0.11 \\
\hline 68 & 81 & 1 & Line & -39.1 & -5 & 39.4 & 100 & 84.8 & 0.05 \\
\hline 35 & 37 & 1 & Line & -33.9 & -15.4 & 37.3 & 100 & 37.3 & 0.16 \\
\hline 35 & 36 & 1 & Line & 0.9 & 6.4 & 6.5 & 100 & 6.7 & 0 \\
\hline 65 & 66 & 1 & $\begin{array}{l}\text { Trans- } \\
\text { former }\end{array}$ & 39.9 & 72.5 & 82.7 & 0 & 0 & 0 \\
\hline 34 & 43 & 1 & Line & 2.7 & 1.5 & 3.1 & 100 & 6.2 & 0.01 \\
\hline 34 & 37 & 1 & Line & -97.3 & -38 & 104.4 & 500 & 21 & 0.29 \\
\hline 62 & 67 & 1 & Line & \begin{tabular}{|l|}
-19.9 \\
\end{tabular} & -15.6 & 25.3 & 100 & 25.3 & 0.15 \\
\hline 62 & 66 & 1 & Line & -32.7 & -18.6 & 37.6 & 100 & 37.6 & 0.64 \\
\hline 34 & 36 & 1 & Line & 30.2 & 11.8 & 32.4 & 100 & 32.4 & 0.09 \\
\hline 33 & 37 & 1 & Line & -17.6 & -10.4 & 20.4 & 100 & 20.4 & 0.17 \\
\hline 60 & 62 & 1 & Line & -6.3 & -7.8 & 10 & 100 & 10 & 0.01 \\
\hline 60 & 61 & 1 & Line & -112 & 8.6 & 112.3 & 500 & 22.5 & 0.33 \\
\hline 59 & 61 & 1 & Line & -48.3 & 4 & 48.5 & 100 & 49.3 & 0.8 \\
\hline 59 & 60 & 1 & Line & \begin{tabular}{|l|}
-39.8 \\
\end{tabular} & 2.5 & 39.9 & 100 & 40.5 & 0.52 \\
\hline 56 & 59 & 2 & Line & -20.1 & $\begin{array}{l}-7.1 \\
\end{array}$ & 21.3 & 100 & 21.3 & 0.38 \\
\hline 56 & 59 & 1 & Line & -20.1 & -7.1 & 21.3 & 0 & 0 & 0.38 \\
\hline 56 & 58 & 1 & Line & -3.8 & -4.8 & 6.1 & 100 & 6.1 & 0.01 \\
\hline 56 & 57 & 1 & Line & -19.3 & -10.6 & 22 & 100 & 22 & 0.17 \\
\hline
\end{tabular}




\begin{tabular}{|c|c|c|c|c|c|c|c|c|c|}
\hline $\begin{array}{c}\text { From } \\
\text { No. }\end{array}$ & $\begin{array}{l}\text { To } \\
\text { No. }\end{array}$ & $\begin{array}{l}\text { Cir- } \\
\text { cuit }\end{array}$ & $\begin{array}{c}\text { Branc } \\
\mathrm{h}\end{array}$ & $\begin{array}{l}\text { MW } \\
\text { From }\end{array}$ & $\begin{array}{l}\text { MVar } \\
\text { From }\end{array}$ & $\begin{array}{l}\text { MVA } \\
\text { From }\end{array}$ & $\begin{array}{l}\text { Line } \\
\text { MVA }\end{array}$ & $\begin{array}{l}\text { \% of MVA } \\
\text { Limit } \\
\text { (Max) }\end{array}$ & $\begin{array}{l}\text { MW } \\
\text { Loss }\end{array}$ \\
\hline 55 & 59 & 1 & Line & -25.3 & -10.9 & 27.6 & 100 & 27.6 & 0.37 \\
\hline 55 & 56 & 1 & Line & -27.9 & -7.4 & 28.9 & 100 & 28.9 & 0.05 \\
\hline 54 & 59 & 1 & Line & -20.8 & -10.2 & 23.2 & 100 & 23.2 & 0.27 \\
\hline 54 & 56 & 1 & Line & 27.6 & -4 & 27.9 & 100 & 27.9 & 0.02 \\
\hline 47 & 69 & 1 & Line & -52.4 & 10 & 53.3 & 100 & 55.6 & 2.39 \\
\hline 53 & 54 & 1 & Line & -14.4 & -4.9 & 15.2 & 100 & 15.2 & 0.06 \\
\hline 51 & 58 & 1 & Line & 15.8 & 4.2 & 16.4 & 100 & 16.8 & 0.08 \\
\hline 49 & 69 & 1 & Line & -43 & 9 & 43.9 & 100 & 46.3 & 1.9 \\
\hline 99 & 100 & 1 & Line & -26.1 & -3.8 & 26.4 & 100 & 26.4 & 0.12 \\
\hline 49 & 54 & 1 & Line & 33 & 13.8 & 35.8 & 0 & 0 & 0.97 \\
\hline 49 & 66 & 1 & Line & -101 & -4.9 & 102 & 500 & 20.8 & 1.78 \\
\hline 49 & 54 & 2 & Line & 33 & 13.8 & 35.8 & 100 & 36.4 & 0.97 \\
\hline 49 & 54 & 1 & Line & 33.1 & 12.1 & 35.3 & 100 & 35.6 & 1.12 \\
\hline 49 & 66 & 1 & Line & -101 & -4.9 & 102 & 0 & 0 & 1.78 \\
\hline 49 & 66 & 2 & Line & -101 & -4.9 & 102 & 500 & 20.8 & 1.78 \\
\hline 56 & 59 & 1 & Line & -21.1 & -7 & 22.3 & 100 & 22.3 & 0.41 \\
\hline 49 & 51 & 1 & Line & 61.6 & 21.3 & 65.2 & 100 & 65.2 & 2 \\
\hline 49 & 50 & 1 & Line & 49.7 & 14.2 & 51.7 & 100 & 51.7 & 0.69 \\
\hline 48 & 49 & 1 & Line & -35 & 3.2 & 35.2 & 100 & 35.5 & 0.21 \\
\hline 63 & 59 & 1 & $\begin{array}{l}\text { Trans- } \\
\text { former }\end{array}$ & 143.2 & 67.9 & 158.5 & 0 & 0 & 0 \\
\hline 50 & 57 & 1 & Line & 32 & 10.2 & 33.6 & 100 & 33.6 & 0.55 \\
\hline 98 & 100 & 1 & Line & -8.72 & 3.3 & 9.3 & 100 & 11.9 & 0.04 \\
\hline 61 & 62 & 1 & Line & 30.8 & -14.9 & 34.2 & 100 & 34.2 & 0.1 \\
\hline 64 & 61 & 1 & $\begin{array}{l}\text { Trans- } \\
\text { former }\end{array}$ & 32.2 & 14.6 & 35.4 & 0 & 0 & 0 \\
\hline 52 & 53 & 1 & Line & 8.6 & 2.6 & 9 & 100 & 10.5 & 0.04 \\
\hline 47 & 49 & 1 & Line & -12.1 & -9.7 & 15.5 & 100 & 15.5 & 0.04 \\
\hline 63 & 64 & 1 & Line & -143 & -67.9 & 158.5 & 500 & 31.7 & 0.43 \\
\hline 64 & 65 & 1 & Line & -175 & -66.9 & 188.2 & 500 & 37.6 & 0.93 \\
\hline 46 & 48 & 1 & Line & -14.9 & -5.8 & 16 & 100 & 16 & 0.14 \\
\hline 65 & 68 & 1 & Line & 7.9 & -21.5 & 22.9 & 100 & 43.5 & 0 \\
\hline 66 & 67 & 1 & Line & 48.6 & 19.9 & 52.5 & 100 & 52.5 & 0.57 \\
\hline 68 & 69 & 1 & $\begin{array}{l}\text { Trans- } \\
\text { former }\end{array}$ & -137 & 113.1 & 177.8 & 0 & 0 & 0 \\
\hline 46 & 47 & 1 & Line & -30.1 & -1.7 & 30.2 & 100 & 30.5 & 0.34 \\
\hline 54 & 55 & 1 & Line & 9.8 & 0.8 & 9.8 & 100 & 10.1 & 0.02 \\
\hline
\end{tabular}




\begin{tabular}{|c|c|c|c|c|c|c|c|c|c|}
\hline $\begin{array}{c}\text { From } \\
\text { No. }\end{array}$ & $\begin{array}{l}\text { To } \\
\text { No. }\end{array}$ & $\begin{array}{l}\text { Cir- } \\
\text { cuit }\end{array}$ & $\begin{array}{c}\text { Branc } \\
\text { h }\end{array}$ & $\begin{array}{l}\text { MW } \\
\text { From }\end{array}$ & $\begin{array}{l}\text { MVar } \\
\text { From }\end{array}$ & $\begin{array}{l}\text { MVA } \\
\text { From }\end{array}$ & $\begin{array}{l}\text { Line } \\
\text { MVA }\end{array}$ & $\begin{array}{c}\text { \% of MVA } \\
\text { Limit } \\
\text { (Max) }\end{array}$ & $\begin{array}{l}\text { MW } \\
\text { Loss }\end{array}$ \\
\hline 69 & 70 & 1 & Line & 104.7 & 16.5 & 106 & 500 & 21.2 & 3.22 \\
\hline 69 & 75 & 1 & Line & 106.7 & 20.4 & 108.6 & 500 & 21.7 & 4.58 \\
\hline 45 & 49 & 1 & Line & -49.3 & -2 & 49.3 & 100 & 51 & 1.7 \\
\hline 45 & 46 & 1 & Line & -35.5 & -3.5 & 35.7 & 100 & 36.1 & 0.52 \\
\hline 80 & 99 & 1 & Line & 16.1 & 8.8 & 18.3 & 100 & 21.1 & 0.17 \\
\hline 80 & 98 & 1 & Line & 25.4 & 9 & 27 & 100 & 27.7 & 0.17 \\
\hline 80 & 97 & 1 & Line & 23.3 & 22.9 & 32.7 & 100 & 33.7 & 0.19 \\
\hline 43 & 44 & 1 & Line & -15.4 & -1.4 & 15.4 & 100 & 16 & 0.15 \\
\hline 51 & 52 & 1 & Line & 26.8 & 6.8 & 27.6 & 100 & 27.7 & 0.17 \\
\hline 42 & 49 & 2 & Line & -50.4 & -1 & 50.4 & 100 & 52.3 & 1.88 \\
\hline 78 & 79 & 1 & Line & -13.4 & -16.4 & 21.2 & 100 & 21.2 & 0.02 \\
\hline 42 & 49 & 1 & Line & -50.4 & -1 & 50.4 & 100 & 52.3 & 1.88 \\
\hline 77 & 82 & 1 & Line & 6 & 7.6 & 9.7 & 100 & 16.8 & 0.05 \\
\hline 77 & 80 & 2 & Line & -70 & -36.1 & 78.7 & 500 & 15.7 & 1 \\
\hline 42 & 49 & 1 & Line & -50.4 & -1 & 50.4 & 0 & 0 & 1.88 \\
\hline 77 & 80 & 1 & Line & -31.9 & -19.1 & 37.2 & 500 & 7.4 & 0.38 \\
\hline 77 & 80 & 1 & Line & -70 & -36.1 & 78.7 & 0 & 0 & 1 \\
\hline 41 & 42 & 1 & Line & -32 & -4.3 & 32.3 & 100 & 32.6 & 0.45 \\
\hline 77 & 78 & 1 & Line & 57.7 & 8.7 & 58.4 & 100 & 58.4 & 0.13 \\
\hline 79 & 80 & 1 & Line & -52.4 & -27.4 & 59.2 & 100 & 59.8 & 0.52 \\
\hline 81 & 80 & 1 & $\begin{array}{l}\text { Trans- } \\
\text { former }\end{array}$ & -39.1 & 75.3 & 84.8 & 0 & 0 & 0 \\
\hline 80 & 96 & 1 & Line & 15.8 & 18.3 & 24.2 & 100 & 27.2 & 0.23 \\
\hline 76 & 118 & 1 & Line & -5.7 & -10.9 & 12.3 & 100 & 12.3 & 0.03 \\
\hline 40 & 42 & 1 & Line & -22.4 & -2.9 & 22.6 & 100 & 22.7 & 0.3 \\
\hline 76 & 77 & 1 & Line & -62.3 & -24.3 & 66.9 & 100 & 70.4 & 2.2 \\
\hline 44 & 45 & 1 & Line & -31.5 & 5.5 & 32 & 100 & 32.5 & 0.24 \\
\hline 40 & 41 & 1 & Line & 5 & 4.6 & 6.8 & 100 & 7.6 & 0.01 \\
\hline 39 & 40 & 1 & Line & 16.1 & -4.2 & 16.6 & 100 & 16.6 & 0.05 \\
\hline 38 & 65 & 1 & Line & -163 & -60.7 & 174.7 & 500 & 34.9 & 2.62 \\
\hline 110 & 112 & 1 & Line & 69.5 & -30.6 & 75.9 & 100 & 75.9 & 1.46 \\
\hline 110 & 111 & 1 & Line & -35.7 & 1 & 35.7 & 100 & 36 & 0.3 \\
\hline 108 & 109 & 1 & Line & 21.8 & -10.4 & 24.2 & 100 & 24.2 & 0.06 \\
\hline 106 & 107 & 1 & Line & 24 & -3.4 & 24.2 & 100 & 24.2 & 0.33 \\
\hline 105 & 108 & 1 & Line & 24 & -10.6 & 26.2 & 100 & 26.2 & 0.19 \\
\hline 105 & 106 & 1 & Line & 8.7 & 4.6 & 9.8 & 100 & 10.4 & 0.02 \\
\hline
\end{tabular}




\begin{tabular}{|c|c|c|c|c|c|c|c|c|c|}
\hline $\begin{array}{c}\text { From } \\
\text { No. }\end{array}$ & $\begin{array}{l}\text { To } \\
\text { No. }\end{array}$ & $\begin{array}{l}\text { Cir- } \\
\text { cuit }\end{array}$ & $\begin{array}{c}\text { Branc } \\
\mathrm{h}\end{array}$ & $\begin{array}{l}\text { MW } \\
\text { From }\end{array}$ & $\begin{array}{l}\text { MVar } \\
\text { From }\end{array}$ & $\begin{array}{l}\text { MVA } \\
\text { From }\end{array}$ & $\begin{array}{l}\text { Line } \\
\text { MVA }\end{array}$ & $\begin{array}{c}\text { \% of MVA } \\
\text { Limit } \\
\text { (Max) }\end{array}$ & $\begin{array}{l}\text { MW } \\
\text { Loss }\end{array}$ \\
\hline 104 & 105 & 1 & Line & 48.7 & 0.1 & 48.7 & 100 & 48.7 & 0.25 \\
\hline 103 & 110 & 1 & Line & 60.6 & 3.2 & 60.6 & 100 & 60.6 & 1.44 \\
\hline 103 & 104 & 1 & Line & 32.3 & 7.9 & 33.3 & 100 & 33.3 & 0.53 \\
\hline 101 & 102 & 1 & Line & -41.8 & 8.2 & 42.5 & 100 & 43.2 & 0.46 \\
\hline 100 & 106 & 1 & Line & 60.6 & 9.2 & 61.3 & 100 & 61.3 & 2.24 \\
\hline 100 & 104 & 1 & Line & 56.4 & 10.6 & 57.4 & 100 & 57.4 & 1.47 \\
\hline 100 & 103 & 1 & Line & 121.1 & -4.3 & 121.2 & 500 & 24.2 & 2.27 \\
\hline 100 & 101 & 1 & Line & -19.5 & 20.9 & 28.6 & 100 & 30.5 & 0.24 \\
\hline 96 & 97 & 1 & Line & -8 & -17.7 & 19.5 & 100 & 19.5 & 0.06 \\
\hline 95 & 96 & 1 & Line & 2.6 & -24.6 & 24.7 & 100 & 24.7 & 0.1 \\
\hline 94 & 100 & 1 & Line & 5.4 & -43.8 & 44.2 & 100 & 44.2 & 0.31 \\
\hline 94 & 96 & 1 & Line & 24.4 & -13 & 27.7 & 100 & 27.7 & 0.2 \\
\hline 94 & 95 & 1 & Line & 44.9 & 6.2 & 45.3 & 100 & 45.3 & 0.28 \\
\hline 93 & 94 & 1 & Line & 49.7 & -18.8 & 53.2 & 100 & 53.2 & 0.63 \\
\hline 92 & 102 & 1 & Line & 47.5 & -6.2 & 47.9 & 100 & 47.9 & 0.28 \\
\hline 92 & 100 & 1 & Line & 34.3 & -15.9 & 37.8 & 100 & 37.8 & 0.86 \\
\hline 92 & 94 & 1 & Line & 57.3 & -14.1 & 59 & 100 & 59 & 1.66 \\
\hline 92 & 93 & 1 & Line & 62.8 & -10.6 & 63.6 & 100 & 63.6 & 1.04 \\
\hline 91 & 92 & 1 & Line & -12.8 & -11.3 & 17.1 & 100 & 17.1 & 0.1 \\
\hline 91 & 90 & 1 & Line & 2.8 & -7.7 & 8.2 & 100 & 8.2 & 0.01 \\
\hline 89 & 92 & 2 & Line & 122.4 & -8.6 & 122.7 & 500 & 24.5 & 1.47 \\
\hline 89 & 92 & 1 & Line & 38.5 & -5.9 & 39 & 500 & 7.8 & 0.58 \\
\hline 89 & 92 & 1 & Line & 122.4 & -8.6 & 122.7 & 0 & 0 & 1.47 \\
\hline 89 & 90 & 2 & Line & 41.9 & -1.9 & 42 & 500 & 8.4 & 0.9 \\
\hline 89 & 90 & 1 & Line & 79.7 & -1.1 & 79.7 & 500 & 15.9 & 1.5 \\
\hline 89 & 90 & 1 & Line & 41.9 & -1.9 & 42 & 0 & 0 & 0.9 \\
\hline 103 & 105 & 1 & Line & $\begin{array}{c}42.98 \\
2 \\
\end{array}$ & 6.5 & 43.4 & 100 & 43.4 & 1.02 \\
\hline 88 & 89 & 1 & Line & $\begin{array}{l}-92.8 \\
\end{array}$ & $\begin{array}{l}-1.8 \\
\end{array}$ & 92.8 & 500 & 18.8 & 1.22 \\
\hline 86 & 87 & 1 & Line & -4 & -14.1 & 14.7 & 0 & 0 & 0.05 \\
\hline 85 & 89 & 1 & Line & -65.2 & 0.9 & 65.2 & 100 & 66.2 & 1.04 \\
\hline 105 & 107 & 1 & Line & 26.7 & -1.8 & 26.8 & 100 & 26.8 & 0.41 \\
\hline 85 & 88 & 1 & Line & -44.4 & 7.7 & 45 & 100 & 45.5 & 0.42 \\
\hline 85 & 86 & 1 & Line & 17.2 & -6.4 & 18.3 & 100 & 18.3 & 0.11 \\
\hline 84 & 85 & 1 & Line & -31.3 & 9.8 & 32.8 & 100 & 33.3 & 0.34 \\
\hline 109 & 110 & 1 & Line & 13.7 & -12.9 & 18.8 & 100 & 18.8 & 0.1 \\
\hline
\end{tabular}




\begin{tabular}{|c|c|c|c|c|c|c|c|c|c|}
\hline $\begin{array}{c}\text { From } \\
\text { No. }\end{array}$ & $\begin{array}{c}\text { To } \\
\text { No. }\end{array}$ & $\begin{array}{c}\text { Cir- } \\
\text { cuit }\end{array}$ & $\begin{array}{c}\text { Branc } \\
\text { h }\end{array}$ & $\begin{array}{c}\text { MW } \\
\text { From }\end{array}$ & $\begin{array}{c}\text { MVar } \\
\text { From }\end{array}$ & $\begin{array}{c}\text { MVA } \\
\text { From }\end{array}$ & $\begin{array}{c}\text { Line } \\
\text { MVA }\end{array}$ & $\begin{array}{c}\text { \% of MVA } \\
\text { Limit } \\
\text { (Max) }\end{array}$ & $\begin{array}{c}\text { MW } \\
\text { Loss }\end{array}$ \\
\hline 83 & 85 & 1 & Line & -36.1 & 13.8 & 38.6 & 100 & 39.6 & 0.67 \\
\hline 83 & 84 & 1 & Line & -19.9 & 15.2 & 25 & 100 & 26.4 & 0.42 \\
\hline 82 & 96 & 1 & Line & -12.4 & 4.6 & 13.2 & 100 & 15.9 & 0.03 \\
\hline 82 & 83 & 1 & Line & -35.7 & 26 & 44.2 & 100 & 46.2 & 0.23 \\
\hline
\end{tabular}

Table C-3 Violations in IEEE 118 bus test system

\begin{tabular}{|c|c|c|c|c|c|c|}
\hline Sr.No & From Number & To Number & Circuit & Xfrmr & Violations & $\begin{array}{c}\text { Max \% Loading } \\
\text { Cont. }\end{array}$ \\
\hline 1 & 4 & 11 & 1 & NO & 1 & 100.27 \\
\hline 2 & 5 & 6 & 1 & NO & 7 & 113.96 \\
\hline 3 & 5 & 11 & 1 & NO & 5 & 130.32 \\
\hline 4 & 8 & 30 & 1 & NO & 57 & 419.78 \\
\hline 5 & 11 & 12 & 1 & NO & 1 & 107.31 \\
\hline 6 & 12 & 14 & 1 & NO & 1 & 106.83 \\
\hline 7 & 12 & 16 & 1 & NO & 1 & 142.04 \\
\hline 8 & 13 & 15 & 1 & NO & 1 & 106.76 \\
\hline 9 & 14 & 15 & 1 & NO & 1 & 119.47 \\
\hline 10 & 16 & 17 & 1 & NO & 1 & 166.25 \\
\hline 11 & 17 & 18 & 1 & NO & 3 & 130.26 \\
\hline 12 & 23 & 24 & 1 & NO & 2 & 109.25 \\
\hline 13 & 23 & 32 & 1 & NO & 9 & 163.27 \\
\hline 14 & 47 & 69 & 1 & NO & 2 & 103.59 \\
\hline 15 & 65 & 68 & 1 & NO & 2 & 291.49 \\
\hline 16 & 68 & 81 & 1 & NO & 2 & 112.45 \\
\hline 17 & 69 & 77 & 1 & NO & 2 & 107.4 \\
\hline 18 & 76 & 77 & 1 & NO & 1 & 115.96 \\
\hline
\end{tabular}

